\title{
Venom-gland Transcriptomic, Venomic, and Antivenomic Profiles of the Spine-bellied Sea Snake (Hydrophis curtus) from the South China Sea
}

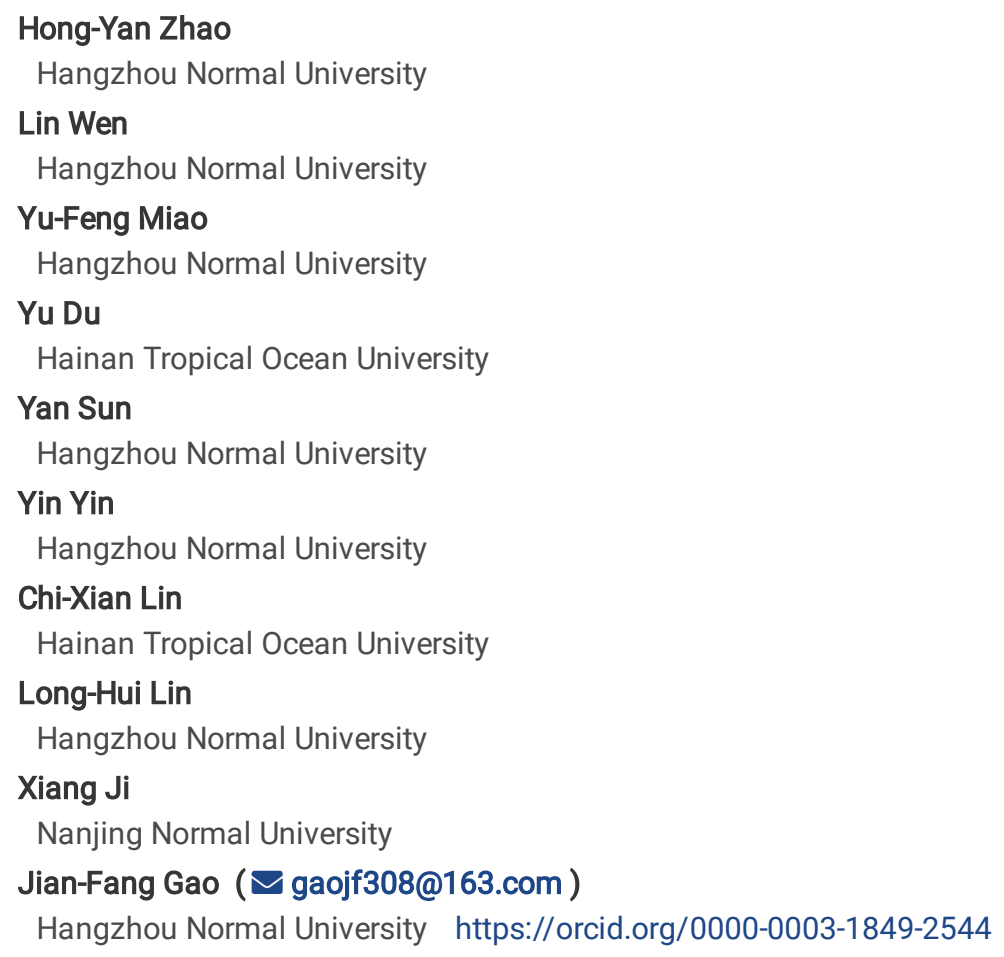

Keywords: Omics, Hydrophis curtus, Snake venom, Transcriptome, Proteome, Antivenomic, Positive selection

Posted Date: November 24th, 2020

DOI: https://doi.org/10.21203/rs.3.rs-112821/v1

License: @ (1) This work is licensed under a Creative Commons Attribution 4.0 International License. Read Full License

Version of Record: A version of this preprint was published at BMC Genomics on July 8th, 2021. See the published version at https://doi.org/10.1186/s12864-021-07824-7. 


\section{Abstract}

Background: A comprehensive evaluation of the -omic profiles of venom is important for understanding the potential function and evolution of snake venom. Here, we conducted an integrated multi-omics-analysis to unveil the venom-transcriptomic and venomic profiles in a same group of spine-bellied sea snakes (Hydrophis curtus) from the South China Sea, where the snake is a widespread species and might generate regionally-specific venom potentially harmful to human activities. The capacity of two heterologous antivenoms to immunocapture the $H$. curtus venom was determined for an in-depth evaluation of their rationality in treatment of $H$. curtus envenomation. In addition, a phylogenetic analysis by maximum likelihood was used to detect the adaptive molecular evolution of full-length toxin-coding unigenes.

Results: A total of 90,909,384 pairs of clean reads were generated via Illumina sequencing from a pooled cDNA library of six specimens, and yielding 148,121 unigenes through de novo assembly. Sequence similarity searching harvested 63,845 valid annotations, including 63,789 non-toxin-coding and 56 toxin-coding unigenes belonging to 22 protein families. Three protein families, three-finger toxins (3-FTx), phospholipase $A_{2}\left(P L A_{2}\right)$, and cysteine-rich secretory protein, were detected in the venom proteome. 3-FTx $(27.15 \%$ in the transcriptome/41.94\% in the proteome) and $\mathrm{PLA}_{2}(59.71 \% / 49.36 \%)$ were identified as the most abundant families in the venom-gland transcriptome and venom proteome. In addition, 24 unigenes from 11 protein families were shown to have experienced positive selection in their evolutionary history, whereas four were relatively conserved throughout evolution. Commercial Naja atra antivenom exhibited a stronger capacity than Bungarus multicinctus antivenom to immunocapture $H$. curtus venom components, especially short neurotoxins, with the capacity of both antivenoms to immunocapture short neurotoxins being weaker than that for $\mathrm{PLA}_{2} \mathrm{~S}$.

Conclusions: Our study clarified the venom-gland transcriptomic and venomic profiles along with the within-group divergence of a $H$. curtus population from the South China Sea. Adaptive evolution of most venom components driven by natural selection appeared to occur rapidly during evolutionary history. Notably, the utility of commercial $N$. atra and $B$. multicinctus antivenoms against $H$. curtus toxins was not comprehensive; thus, the development of species-specific antivenom is urgently needed.

\section{Background}

Sea snakes, the largest group of current marine reptiles, are widely distributed in many tropical and subtropical waters throughout the IndoPacific Ocean [1, 2]. Sea snakes display a diverse array of morphological, physiological, and behavioural traits modified for secondary adaptation to the marine environment; e.g., the venom has evolved to be biochemically simple despite comprising a pharmacologically toxic arsenal $[3,4]$. It is generally believed that the adaptive evolution of snake venom composition and function is heavily propelled by natural selection from dietary shift, which might be accompanied by gene birth-and-death processes at the molecular level. A typical case is the shift of the marbled sea snake (Aipysurus eydouxii) to trophic specialisation for fish eggs, which involved the dinucleotide deletion of neurotoxin genes and consequently the loss of primary neurotoxic activity in the venom [5]. Defining the venom profiles at the transcriptomic and proteomic levels is helpful for understanding the adaptive evolution and functional complexity of sea snake venom, as well as managing the envenomation caused by sea snakes and, exploring the medically important components and designing the antivenoms against sea snake venom. However, owing to the relatively ambiguous taxonomy of sea snakes, little attention has been paid to snakebites caused by sea snakes and few investigations have been conducted to uncover the profiles of sea snake venom at the '-omics' level. Sea snake venom was previously shown to be mainly composed of three-finger toxins (3-FTx; 26.3-86.9\%) and phospholipase A2s (PLA ${ }_{2}$ s; $10.9-66.7 \%$ ) that vary between and within species $[3,4,6-10]$. Generally, the diversity of the venom proteome is closely related to the profiles of toxin-coding genes, with the sequence conservation of these genes varying during evolutionary history [11]. Therefore, detecting the strength of natural selection on toxin-coding genes together with their homologs would be helpful in explaining the diversity of the venom proteome. Moreover, transcriptional and translational regulation along with post-translational modification is also considered to affect the diverse evolution of venom components. In particular, the abundance and type of toxin transcripts from the venom gland are highly concordant with the venom proteins in several snakes but extremely divergent in others [11-18]. For example, the toxin-coding genes detected in the venom gland of the spine-bellied sea snake (Hydrophis curtus; formerly Lapemis curtus) are not well correlated with the secreted venom proteins $[6,8,19]$. Nevertheless, such a divergence is deduced according to the venom-gland transcriptomic and venom proteomic data on $H$. curtus specimens from different regions, and still requires in-depth verification using specimens from the same region.

As most sea snakes are usually benign unless they are provoked, the incidence of sea snake bites is much lower than that caused by terrestrial venomous snakes $[4,20,21]$. Actually, over a half of the sea snake bites are related to professional fishing because sea snakes constitute a consistent by-catch of tropical trawl fisheries and the fishermen can get bitted by sea snakes when handling the fishing net [2224]. It is estimated that significant envenomation and death occur in approximately $20 \%$ and $3 \%$ of sea snake bites, respectively [24], with the death rate reaching $50 \%$ if the victims are not properly treated [25]. The clinical manifestations of sea snake envenomation are mainly due to the effects of neurotoxins and $\mathrm{PLA}_{2} \mathrm{~S}$, which can induce systematic symptoms (e.g. paralysis, dysphagia, respiratory failure, and myonecrosis) $[24,25]$. Only a single sea snake antivenom is currently commercially available, which is prepared against Hydrophis schistosa (formerly 
Enhydrina schistosa) venom by Seqirus and is effective in the treatment of envenomation caused by a wide variety of sea snakes [26, 27]. Practically, however, not all victims envenomed by sea snakes receive an injection of sea snake antivenom. In China, for example, sea snakebites are predominantly caused by $H$. cutus and Hydrophis cyanocinctus, but the patients are either treated with traditional Chinese and western medicine or receive injections of many-banded krait Bungarus multicinctus and Chinese cobra Naja atra antivenoms [28, 29]. Nevertheless, the efficacy and safety of such therapeutic schedules based on antivenoms from phylogenetically related species have yet to be estimated thoroughly.

Hydrophis curtus is the most important of the 16 species of sea snakes in China in terms of the quantity and distribution [30]. This species potentially causes severe illness or death even though it is not defined as a medically important venomous snake by the World Health Organization. In this study, we therefore applied a strategy combining next-generation sequencing technology and proteomic analysis to unveil the toxin profiles in the venom-gland transcriptome and venom proteome of $H$. curtus from the South China Sea. The strength of natural selection experienced during the evolutionary history of toxins was tested based on the identified toxin-coding unigenes. Moreover, antivenomic analysis, ELISA and western blotting were used to evaluate and compare the capacity of commercial $B$. multicinctus and $N$. atra antivenoms to immunocapture $H$. curtus venom components.

\section{Results}

\section{Sequencing and de novo assembly}

A total of 90,909,384 pairs of clean reads were filtered from 93,226,644 pairs of raw reads generated from Illumina sequencing of the venom gland cDNA library of $H$. curtus, derived from six $H$. curtus individuals captured as by-catch from the South China Sea, and assembled into 284,495 transcripts (N50/N90 = 1,763/290) using Trinity. Subsequently, 148,121 unigenes (N50/N90 = 2,229/580) were clustered from these transcripts using Corset, among which 88,806 unigenes passed the quality filter (FPKM > 1). Following similarity alignment between unigenes and sequences in NCBI non-redundant protein (NR)/nucleotide (NT) and Uniprot databases (strict to Serpentes) using Diamond and BLAST, the assemblies were finally categorized into toxin $(56)$, non-toxin $(63,789)$, and unidentified $(24,961)$ groups. The toxin group was expressed at markedly higher redundancies (50,456.48 FPKM/unigene) than those of the non-toxin group (18.02 FPKM/unigene). Moreover, the toxin group comprised only 56 unigenes but accounted for $68 \%$ of the total abundance expressed in FPKM of the $H$. curtus transcriptome, whereas the non-toxin and unidentified groups accounted for $27.7 \%$ and $4.3 \%$, respectively (Fig. 1 ).

\section{Venom-gland transcriptomic profile}

A total of 22 protein families were derived from 56 toxin-coding unigenes with partial and complete CDS using bioinformatics analyses (Fig. 1 and Additional file Table S1). Three toxin families including PLA 2 (59.71\%), 3-FTx (27.15\%), and cysteine-rich secretory protein (CRISP, $12.82 \%)$ appeared to dominate the toxin constituents. The remaining 19 toxin families were only expressed at low abundance with a total FPKM of $0.32 \%$, including snake venom metalloproteinase (SVMP), C-type lectin (CTL), snake venom serine proteinase (SVSP), cysteine-type inhibitor (cystatin), phospholipase B (PLB), phosphodiesterase (PDE), hyaluronidase (HA), $5 \dot{c}$ nucleotidase (5çNT), PLA 2 inhibitor, cysteinerich with EGF-like domain (CREGF), vascular endothelial growth factor (VEGF), venom factor, aminopeptidase, nerve growth factor (NGF), acetylcholinesterase (AchE), metalloproteinase inhibitor (MP), waprin, glutaminyl-peptide cyclotransferases (QC), and I-amino acid oxidase (Fig. 1). The relative abundance and sequences of toxin unigenes, arranged according to toxin family, are listed in Additional file Tables S1 and S2.

\section{Venom proteomic profile}

Eleven chromatographic fractions (peaks) were resolved in crude $H$. curtus venom by RP-HPLC and 32 protein bands from gels were identified by MS analysis (Fig. 2 and Table 1). The proteomic analysis showed that $H$. curtus venom was dominated by three toxin families including $\mathrm{PLA}_{2}$ (49.36\%), 3-FTx (41.94\%), and CRISP (8.70\%) (Fig. 3 and Table 1). Specifically, chromatographic peaks 1-4 contained 3-FTx accounting for $40.37 \%$ of the total venom protein, peaks 5-10 contained PLA 2 (49.36\%) at high abundance and 3-FTx (1.57\%) at very low abundance, and peak 11 contained only CRISP. Additionally, acidic PLA 2 (36.08\%) and short-neurotoxin (SNX, 33.13\%) were the predominant components in PLA 2 and 3-FTx families, respectively. 
Table 1

Assignment of the chromatographic fractions and electrophoretic bands from $H$. curtus venom to protein families.

\begin{tabular}{|c|c|c|c|c|c|c|}
\hline \multirow[t]{2}{*}{ Peak } & \multirow[t]{2}{*}{$\%$} & \multirow{2}{*}{$\begin{array}{l}\mathrm{MW} \\
(\mathrm{kDa})\end{array}$} & \multicolumn{2}{|c|}{ Peptide Ion } & \multirow[t]{2}{*}{ MS/MS-derived sequence } & \multirow{2}{*}{$\begin{array}{l}\text { Protein } \\
\text { family/species/accession/transcript } \\
\text { ID }\end{array}$} \\
\hline & & & $\mathrm{m} / \mathrm{z}$ & $z$ & & \\
\hline \multirow[t]{8}{*}{1} & \multirow[t]{8}{*}{33.13} & \multirow[t]{8}{*}{12.9} & 401.2 & 2 & TWSDHR & \multirow{8}{*}{$\begin{array}{l}\text { 3-FTx (SNX); Hydrophis schistosus; } \\
\text { P68415; Hcu|50480 }\end{array}$} \\
\hline & & & 650.8 & 2 & GCGCPBVBPGXB & \\
\hline & & & 669.3 & 2 & TCCNBBSSBPB & \\
\hline & & & 711.3 & 2 & TTTNCAESSCYB & \\
\hline & & & 734.8 & 2 & MTCCNBBSSBPB & \\
\hline & & & 742.8 & 2 & $\underline{\text { MTCCNBBSSBPB }}$ & \\
\hline & & & 517.2 & 3 & TTTNCAESSCYBB & \\
\hline & & & 775.3 & 2 & TTTNCAESSCYBB & \\
\hline \multirow[t]{6}{*}{2} & \multirow[t]{2}{*}{3.05} & \multirow[t]{2}{*}{13.3} & 1275.5 & 1 & SWCDAFCSSR & \multirow{2}{*}{$\begin{array}{l}\text { 3-FTx (LNX); Hydrophis hardwickii; } \\
\text { A3FM53; Hcul53057 }\end{array}$} \\
\hline & & & 2190.0 & 1 & THPYBPETCPPGBNXCYB & \\
\hline & \multirow[t]{4}{*}{1.56} & \multirow[t]{4}{*}{11.5} & 1275.5 & 1 & SWCDAFCSSR & \multirow{4}{*}{$\begin{array}{l}\text { 3-FTx (LNX); H. hardwickii; A3FM53; } \\
\text { Hcul54185 }\end{array}$} \\
\hline & & & 1403.6 & 1 & BSWCDAFCSSR & \\
\hline & & & 2055.9 & 1 & DXNCCATDNCNTVANWB & \\
\hline & & & 2190.0 & 1 & THPYBPETCPPGBNXCYB & \\
\hline \multirow[t]{2}{*}{3} & 1.39 & 13.8 & 1245.5 & 1 & SWCDAFCGSR & $\begin{array}{l}\text { 3-FTx (LNX); H. hardwickii; Q8UW28; } \\
\text { Hcul53057 }\end{array}$ \\
\hline & 0.90 & 12.0 & 1245.5 & 1 & SWCDAFCGSR & $\begin{array}{l}\text { 3-FTx (LNX); H. hardwickii; Q8UW28; } \\
\text { Hcul53057 }\end{array}$ \\
\hline \multirow[t]{9}{*}{4} & 0.14 & 16.8 & 1245.5 & 1 & SWCDAFCGSR & $\begin{array}{l}\text { 3-FTx (LNX); H. hardwickii; Q8UW28; } \\
\text { Hcul53057 }\end{array}$ \\
\hline & 0.03 & 14.7 & 1245.5 & 1 & SWCDAFCGSR & $\begin{array}{l}\text { 3-FTx (LNX); H. hardwickii; Q8UW28; } \\
\text { Hcul53057 }\end{array}$ \\
\hline & \multirow[t]{3}{*}{0.04} & \multirow[t]{3}{*}{13.8} & 1275.5 & 1 & SWCDAFCSSR & \multirow{3}{*}{$\begin{array}{l}\text { 3-FTx (LNX); H. hardwickir; Q8UW29; } \\
\text { Hcul51842 }\end{array}$} \\
\hline & & & 1403.6 & 1 & BSWCDAFCSSR & \\
\hline & & & 2053.0 & 1 & TPYBPETCPPGBNXCYB & \\
\hline & \multirow[t]{4}{*}{0.13} & \multirow[t]{4}{*}{12.3} & 1275.5 & 1 & SWCDAFCSSR & \multirow{4}{*}{$\begin{array}{l}\text { 3-FTx (LNX); H. hardwickii; A3FM53; } \\
\text { Hcul54185 }\end{array}$} \\
\hline & & & 1403.6 & 1 & BSWCDAFCSSR & \\
\hline & & & 2055.9 & 1 & DXNCCATDNCNTVANWB & \\
\hline & & & 2190.0 & 1 & THPYBPETCPPGBNXCYB & \\
\hline \multirow[t]{5}{*}{5} & \multirow[t]{5}{*}{1.05} & \multirow[t]{5}{*}{25.3} & 1336.6 & 1 & XHDDCYGEAEB & \multirow{5}{*}{$\begin{array}{l}\mathrm{PLA}_{2} ; \text { H. schistosus; P00610; } \\
\mathrm{Hcu|} 52733\end{array}$} \\
\hline & & & 1514.7 & 1 & NAYNNANYNXDTB & \\
\hline & & & 1878.9 & 1 & NXVBFSYVXTCANHNR & \\
\hline & & & 1936.0 & 1 & NXVBFSYVXTCANHNR & \\
\hline & & & 2785.2 & 1 & SSXDYADYGCYCGAGGSGTPVDEXDR & \\
\hline
\end{tabular}




\begin{tabular}{|c|c|c|c|c|c|c|}
\hline \multirow[t]{2}{*}{ Peak } & \multirow[t]{2}{*}{$\%$} & \multirow{2}{*}{$\begin{array}{l}\mathrm{MW} \\
(\mathrm{kDa})\end{array}$} & \multicolumn{2}{|c|}{ Peptide Ion } & \multirow[t]{2}{*}{ MS/MS-derived sequence } & \multirow{2}{*}{$\begin{array}{l}\text { Protein } \\
\text { family/species/accession/transcript } \\
\text { ID }\end{array}$} \\
\hline & & & $\mathrm{m} / z$ & $z$ & & \\
\hline & \multirow[t]{6}{*}{0.33} & \multirow[t]{6}{*}{21.1} & 1336.6 & 1 & XHDDCYGEAEB & \multirow{6}{*}{$\begin{array}{l}\mathrm{PLA}_{2} ; \text { H. schistosus, P00610; } \\
\text { Hcu|52733 }\end{array}$} \\
\hline & & & 1514.7 & 1 & NAYNNANYNXDTB & \\
\hline & & & 1878.9 & 1 & NXVBFSYVXTCANHNR & \\
\hline & & & 1936.0 & 1 & NXVBFSYVXTCANHNR & \\
\hline & & & 2069.9 & 1 & XHDDCYGEAEBBGCYPB & \\
\hline & & & 2785.2 & 1 & SSXDYADYGCYCGAGGSGTPVDEXDR & \\
\hline & \multirow[t]{4}{*}{1.14} & \multirow[t]{4}{*}{16.9} & 1336.6 & 1 & XHDDCYGEAEB & \multirow{4}{*}{$\begin{array}{l}\mathrm{PLA}_{2} ; \text { H. schistosus; P00610; } \\
\text { Hcu|52733 }\end{array}$} \\
\hline & & & 1514.7 & 1 & NAYNNANYNXDTB & \\
\hline & & & 1878.9 & 1 & NXVBFSYVXTCANHNR & \\
\hline & & & 2785.1 & 1 & SSXDYADYGCYCGAGGSGTPVDEXDR & \\
\hline & \multirow[t]{4}{*}{0.15} & \multirow[t]{4}{*}{14.8} & 1336.6 & 1 & XHDDCYGEAEB & \multirow{4}{*}{$\begin{array}{l}\mathrm{PLA}_{2} ; \text { H. hardwickii; Q8UW30; } \\
\text { Hcu|52733 }\end{array}$} \\
\hline & & & 1514.7 & 1 & NAYNNANYNXDTB & \\
\hline & & & 1955.8 & 1 & MXXYDYDCGSNGPYCB & \\
\hline & & & 2785.2 & 1 & SSXDYADYGCYCGAGGSGTPVDEXDR & \\
\hline & \multirow[t]{3}{*}{0.27} & \multirow[t]{3}{*}{13.9} & 1275.5 & 1 & SWCDAFCSSR & \multirow{3}{*}{$\begin{array}{l}\text { 3-FTx (LNX); H. hardwickii; Q8UW29; } \\
\text { Hcul51842 }\end{array}$} \\
\hline & & & 1403.6 & 1 & BSWCDAFCSSR & \\
\hline & & & 2053.0 & 1 & TPYBPETCPPGBNXCYB & \\
\hline & 1.16 & 12.6 & 1275.5 & 1 & SWCDAFCSSR & $\begin{array}{l}\text { 3-FTx (LNX); H. hardwickii; Q8UW29; } \\
\text { Hcul51395 }\end{array}$ \\
\hline \multirow[t]{8}{*}{6} & \multirow[t]{3}{*}{1.56} & \multirow[t]{3}{*}{19.1} & 1514.7 & 1 & NAYNNANYNXDTB & \multirow{3}{*}{$\begin{array}{l}\text { PLA } ; \text {; H. schistosus; P00610; } \\
\text { Hcu|52733 }\end{array}$} \\
\hline & & & 1879.0 & 1 & NXVBFSYVXTCANHNR & \\
\hline & & & 1936.0 & 1 & NXVBFSYVXTCANHNR & \\
\hline & \multirow[t]{5}{*}{8.34} & \multirow[t]{5}{*}{16.9} & 1336.6 & 1 & XHDDCYGEAEB & \multirow{5}{*}{$\begin{array}{l}\mathrm{PLA}_{2} ; \text { H. schistosus; P00610; } \\
\text { Hcu|52499 }\end{array}$} \\
\hline & & & 1514.7 & 1 & NAYNNANYNXDTB & \\
\hline & & & 1878.9 & 1 & NXVBFSYVXTCANHNR & \\
\hline & & & 1936.0 & 1 & NXVBFSYVXTCANHNR & \\
\hline & & & 2785.1 & 1 & SSXDYADYGCYCGAGGSGTPVDEXDR & \\
\hline \multirow[t]{10}{*}{7} & \multirow[t]{3}{*}{0.33} & 18.9 & 1336.6 & 1 & XHDDCYGEAEB & $\mathrm{PLA}_{2}$; H. schistosus, P00610; \\
\hline & & & 1514.7 & 1 & NAYNNANYNXDTB & \\
\hline & & & 1936.0 & 1 & NXVBFSYVXTCANHNR & \\
\hline & 0.25 & 16.4 & 1336.6 & 1 & XHDDCYGEAEB & $\mathrm{PLA}_{2}$; H. schistosus; P00610; \\
\hline & & & 1514.7 & 1 & NAYNNANYNXDTB & $\mathrm{Ho}$ \\
\hline & & & 1879.0 & 1 & NXVBFSYVXTCANHNR & \\
\hline & & & 1936.0 & 1 & NXVBFSYVXTCANHNR & \\
\hline & & & 2785.2 & 1 & SSXDYADYGCYCGAGGSGTPVDEXDR & \\
\hline & 0.12 & 14.5 & 1936.0 & 1 & NXVBFSYVXTCANHNR & $\begin{array}{l}\mathrm{PLA}_{2} ; \text { H. schistosus; P00610; } \\
\text { Hcu|52837 }\end{array}$ \\
\hline & 0.15 & 12.0 & 1245.5 & 1 & SWCDAFCGSR & $\begin{array}{l}\text { 3-FTx (LNX); H. hardwickii; Q8UW28; } \\
\text { Hcul53057 }\end{array}$ \\
\hline
\end{tabular}




\begin{tabular}{|c|c|c|c|c|c|c|}
\hline \multirow[t]{2}{*}{ Peak } & \multirow[t]{2}{*}{$\%$} & \multirow{2}{*}{$\begin{array}{l}\text { MW } \\
(\mathrm{kDa})\end{array}$} & \multicolumn{2}{|c|}{ Peptide lon } & \multirow[t]{2}{*}{ MS/MS-derived sequence } & \multirow{2}{*}{$\begin{array}{l}\text { Protein } \\
\text { family/species/accession/transcript } \\
\text { ID }\end{array}$} \\
\hline & & & $\mathrm{m} / \mathrm{z}$ & $z$ & & \\
\hline \multirow[t]{14}{*}{8} & \multirow[t]{11}{*}{19.26} & \multirow[t]{11}{*}{16.1} & 528.2 & 2 & AFXCNCDR & \multirow{11}{*}{$\begin{array}{l}\mathrm{PLA}_{2} ; \text { H. hardwickii; Q8UW31; } \\
\text { Hcu|52837 }\end{array}$} \\
\hline & & & 429.9 & 3 & NMXBCANHGSR & \\
\hline & & & 644.3 & 2 & NMXBCANHGSR & \\
\hline & & & 435.2 & 3 & NMXBCANHGSR & \\
\hline & & & 652.3 & 2 & NMXBCANHGSR & \\
\hline & & & 668.8 & 2 & XHDDCYGEAEB & \\
\hline & & & 692.3 & 2 & TAAXCFAGAPYNB & \\
\hline & & & 644.3 & 3 & DNNDECBAFXCNCDR & \\
\hline & & & 965.9 & 2 & DNNDECBAFXCNCDR & \\
\hline & & & 829.7 & 3 & TAAXCFAGAPYNBENYNXDXNB & \\
\hline & & & 986.4 & 3 & $\underline{\text { MTXDYMDYGCYCGTGGSGTPVDEXDR }}$ & \\
\hline & \multirow[t]{2}{*}{5.03} & \multirow[t]{2}{*}{15.4} & 1055.5 & 1 & AFXCNCDR & \multirow{2}{*}{$\begin{array}{l}\mathrm{PLA}_{2} ; \text { H. hardwickii; Q8UW31; } \\
\text { Hcu|52837 }\end{array}$} \\
\hline & & & 1383.7 & 1 & TAAXCFAGAPYNB & \\
\hline & 10.67 & 14.4 & 1383.7 & 1 & TAAXCFAGAPYNB & $\begin{array}{l}\mathrm{PLA}_{2} ; \text { H. hardwickii; Q8UW31; } \\
\text { Hcu|52515 }\end{array}$ \\
\hline \multirow[t]{20}{*}{9} & \multirow[t]{18}{*}{0.31} & \multirow[t]{18}{*}{73.0} & 561.8 & 2 & ENYNXDXNB & \multirow{18}{*}{$\begin{array}{l}\mathrm{PLA}_{2} ; \text { H. hardwickii, Q8UW31; } \\
\text { Hcu|52733 }\end{array}$} \\
\hline & & & 587.3 & 2 & MXBCANHGSR & \\
\hline & & & 516.6 & 3 & ENYNXDXNBHCB & \\
\hline & & & 429.9 & 3 & NMXBCANHGSR & \\
\hline & & & 652.3 & 2 & NMXBCANHGSR & \\
\hline & & & 692.3 & 2 & TAAXCFAGAPYNB & \\
\hline & & & 809.4 & 2 & XHDDCYGEAEBXPA & \\
\hline & & & 680.8 & 2 & GTGGSGTPVDEXDR & \\
\hline & & & 760.8 & 2 & CGTGGSGTPVDEXDR & \\
\hline & & & 694.3 & 3 & NXYBFBNMXBCANHGSR & \\
\hline & & & 699.7 & 3 & NXYBFBNMXXCANHGSR & \\
\hline & & & 829.7 & 3 & TAAXCFAGAPYNBENYNXDXNB & \\
\hline & & & 978.4 & 3 & MTXDYMDYGCYCGTGGSGTPVDEXDR & \\
\hline & & & 983.7 & 3 & $\underline{\text { MTXDYMDYGCYCGTGGSGTPVDEXDR }}$ & \\
\hline & & & 983.7 & 3 & MTXDYMDDYGCYCGTGGSGTPVDEXDR & \\
\hline & & & 1483.1 & 2 & 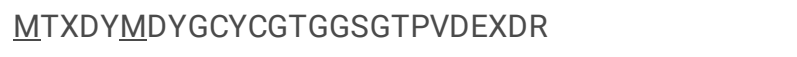 & \\
\hline & & & 1092.0 & 4 & XPACNYMXXGPYYNXYTYDCVEHBXTCBDNNDECB & \\
\hline & & & 962.2 & 5 & XHDDCYGEAEBXPACNYMXSGPYYNXYTYDCVEHBXTCB & \\
\hline & \multirow[t]{2}{*}{0.29} & \multirow[t]{2}{*}{15.9} & 1055.5 & 1 & AFXCNCDR & \multirow{2}{*}{$\begin{array}{l}\text { PLA }_{2} ; \text { H. hardwickii; Q8UW31; } \\
\text { Hcu|52733 }\end{array}$} \\
\hline & & & 1383.7 & 1 & TAAXCFAGAPYNB & \\
\hline
\end{tabular}




\begin{tabular}{|c|c|c|c|c|c|c|}
\hline \multirow[t]{2}{*}{ Peak } & \multirow[t]{2}{*}{$\%$} & \multirow{2}{*}{$\begin{array}{l}\text { MW } \\
(\mathrm{kDa})\end{array}$} & \multicolumn{2}{|c|}{ Peptide Ion } & \multirow[t]{2}{*}{ MS/MS-derived sequence } & \multirow{2}{*}{$\begin{array}{l}\text { Protein } \\
\text { family/species/accession/transcript } \\
\text { ID }\end{array}$} \\
\hline & & & $\mathrm{m} / z$ & $z$ & & \\
\hline & \multirow[t]{21}{*}{0.19} & \multirow[t]{21}{*}{14.6} & 528.2 & 2 & AFXCNCDR & \multirow{21}{*}{$\begin{array}{l}\mathrm{PLA}_{2} ; \text { H. hardwickii; Q8UW31; } \\
\text { Hcu|52837 }\end{array}$} \\
\hline & & & 561.8 & 2 & ENYNXDXNB & \\
\hline & & & 644.3 & 2 & NMXBCANHGSR & \\
\hline & & & 429.9 & 3 & NMXBCANHGSR & \\
\hline & & & 652.3 & 2 & NMXBCANHGSR & \\
\hline & & & 435.2 & 3 & NMXBCANHGSR & \\
\hline & & & 668.8 & 2 & XHDDCYGEAEB & \\
\hline & & & 692.3 & 2 & TAAXCFAGAPYNB & \\
\hline & & & 774.3 & 2 & ENYNXDXNBHCB & \\
\hline & & & 595.6 & 3 & CCBXHDDCYGEAEB & \\
\hline & & & 965.9 & 2 & DNNDECBAFXCNCDR & \\
\hline & & & 829.7 & 3 & TAAXCFAGAPYNBENYNXDXNB & \\
\hline & & & 978.4 & 3 & MTXDYMDYGCYCGTGGSGTPVDEXDR & \\
\hline & & & 1467.1 & 2 & MTXDYMDYGCYCGTGGSGTPVDEXDR & \\
\hline & & & 989.1 & 3 & $\underline{M} T X D Y M D Y G C Y C G T G G S G T P V D E X D R$ & \\
\hline & & & 1475.1 & 2 & MTXDYMDYGCYCGTGGSGTPVDEXDR & \\
\hline & & & 1158.5 & 3 & XPACNYMXSGPYYNXYTYDCVEHBXTCB & \\
\hline & & & 1163.8 & 3 & XPACNYMXSGPYYNXYTYDCVEHBXTCB & \\
\hline & & & 1092.0 & 4 & XPACNYMXXGPYYNXYTYDCVEHBXTCBDNNDECB & \\
\hline & & & 959.0 & 5 & XHDDCYGEAEBXPACNYMXSGPYYNXYTYDCVEHBXTCB & \\
\hline & & & 1198.5 & 4 & XHDDCYGEAEBXPACNYMXSGPYYNXYTYDCVEHBXTCB & \\
\hline
\end{tabular}




\begin{tabular}{|c|c|c|c|c|c|c|}
\hline \multirow[t]{2}{*}{ Peak } & \multirow[t]{2}{*}{$\%$} & \multirow{2}{*}{$\begin{array}{l}\text { MW } \\
(\mathrm{kDa})\end{array}$} & \multicolumn{2}{|c|}{ Peptide lon } & \multirow[t]{2}{*}{ MS/MS-derived sequence } & \multirow{2}{*}{$\begin{array}{l}\text { Protein } \\
\text { family/species/accession/transcript } \\
\text { ID }\end{array}$} \\
\hline & & & $\mathrm{m} / z$ & $z$ & & \\
\hline \multirow[t]{19}{*}{10} & \multirow[t]{19}{*}{0.33} & \multirow[t]{19}{*}{16.0} & 561.8 & 2 & ENYNXDXNB & \multirow{19}{*}{$\begin{array}{l}\mathrm{PLA}_{2} ; \text { H. hardwickii; Q8UW31; } \\
\text { Hcu|52837 }\end{array}$} \\
\hline & & & 644.3 & 2 & NMXBCANHGSR & \\
\hline & & & 435.2 & 3 & NMXBCANHGSR & \\
\hline & & & 652.3 & 2 & NMXBCANHGSR & \\
\hline & & & 668.8 & 2 & XHDDCYGEAEB & \\
\hline & & & 692.3 & 2 & TAAXCFAGAPYNB & \\
\hline & & & 516.6 & 3 & ENYNXDXNBHCB & \\
\hline & & & 774.3 & 2 & ENYNXDXNBHCB & \\
\hline & & & 644.3 & 3 & DNNDECBAFXCNCDR & \\
\hline & & & 965.9 & 2 & DNNDECBAFXCNCDR & \\
\hline & & & 829.7 & 3 & TAAXCFAGAPYNBENYNXDXNB & \\
\hline & & & 728.8 & 4 & TAAXCFAGAPYNBENYNXDXNBHCB & \\
\hline & & & 971.4 & 3 & TAAXCFAGAPYNBENYNXDXNBHCB & \\
\hline & & & 983.7 & 3 & MTXDYMDYGCYCGTGGSGTPVDEXDR & \\
\hline & & & 989.0 & 3 & $\underline{M} T X D Y M D Y G C Y C G T G G S G T P V D E X D R$ & \\
\hline & & & 1475.0 & 2 & $\underline{\text { MTXDYMDYGCYCGTGGSGTPVDEXDR }}$ & \\
\hline & & & 1092.0 & 4 & XPACNYMXSGPYYNXYTYDCVEHBXTCBDNNDECB & \\
\hline & & & 962.2 & 5 & XHDDCYGEAEBXPACNYMXSGPYYNXYTYDCVEHBXTCB & \\
\hline & & & 1202.5 & 4 & XHDDCYGEAEBXPACNYMXSGPYYNXYTYDCVEHBXTCB & \\
\hline \multirow[t]{11}{*}{11} & \multirow[t]{7}{*}{4.21} & \multirow[t]{7}{*}{27.1} & 964.5 & 1 & CBTEWXB & \multirow{7}{*}{$\begin{array}{l}\text { CRISP; H. hardwickii; Q8UW11; } \\
\text { Hcul52188 }\end{array}$} \\
\hline & & & 1092.6 & 1 & BCBTEWXB & \\
\hline & & & 1126.6 & 1 & WNSHAABNAB & \\
\hline & & & 1194.7 & 1 & EXVDBHNAXR & \\
\hline & & & 1342.6 & 1 & CTFAHSPEHTR & \\
\hline & & & 1509.6 & 1 & SBCPATCFCHNB & \\
\hline & & & 1776.8 & 1 & YXYVCBYCPAGNXR & \\
\hline & \multirow[t]{2}{*}{0.55} & \multirow[t]{2}{*}{18.5} & 1342.6 & 1 & CTFAHSPEHTR & \multirow{2}{*}{$\begin{array}{l}\text { CRISP; H. hardwickii; Q8UW11; } \\
\text { Hcul52188 }\end{array}$} \\
\hline & & & 1776.8 & 1 & YXYVCBYCPAGNXR & \\
\hline & 0.74 & 17.2 & 1342.6 & 1 & CTFAHSPEHTR & $\begin{array}{l}\text { CRISP; H. hardwickii; Q8UW11; } \\
\text { Hcul52570 }\end{array}$ \\
\hline & 3.20 & 16.1 & 1776.8 & 1 & YXYVCBYCPAGNXR & $\begin{array}{l}\text { CRISP; H. hardwickii; Q8UW11; } \\
\text { Hcul52188 }\end{array}$ \\
\hline \multicolumn{7}{|c|}{ X: Leu/Ile; B: Lys/GIn. Methionine oxidation is underlined. } \\
\hline $\begin{array}{l}3-\mathrm{F} 7 \\
\text { neu }\end{array}$ & & . & $\mathrm{A}_{2}, \mathrm{pr}$ & & $\begin{array}{l}\text { ase } A_{2} \text {; CRISP, cysteine-rich secretory protein; LNX, long } \\
\text { ditional file S2. }\end{array}$ & a-neurotoxin; SNX, short \\
\hline
\end{tabular}

Moreover, as the proteins identified by MS could be assigned to 11 toxin-coding transcripts of three families (Table 1), the correlation between transcript and protein abundances of individual genes for each toxin family was further evaluated. Non-parametric correlation analysis revealed a weak correlation between both abundances of these 11 toxins with a low Spearman's rank correlation coefficient $(\rho=0.30)$, 
whereas linear regression analysis indicated no correlation $\left(F_{1,9}=0.49, P=0.51\right)$ with very low Pearson's correlation coefficient $(R=0.23)$. In particular, extreme divergence between transcript and protein abundances could be observed for SNX (Fig. 3 and Table S1). When the analyses were conducted again by excluding SNX, a strong correlation between the abundances of the remaining 10 toxins was detected using non-parametric correlation analysis with $\rho=0.73$ in addition to linear regression analysis $\left(F_{1,8}=21.8, P=0.002\right)$ with $R=0.86$.

\section{Adaptive molecular selection}

Considering that not all full-length toxin-coding unigenes could be aligned with multiple homologous sequences with full CDS, we used either codeml or yn00 in PAML 4.8 to evaluate the potential for adaptive natural selection. Furthermore, one unigene (AMP) was excluded from the selection analysis because of the lack of homologs with full CDS. As excessive sequence divergence might reduce the power of the likelihoodratio test [31], the unigenes from the same toxin family were divided into several groups at a threshold of $10 \%$ nucleotide sequence divergence and codeml analysis was conducted separately with their homologs. In total, 23 tests were performed using the codeml program on 15 toxin families including 30 full-length unigenes, with a significance level of 0.002 following Bonferroni correction (Table 2 and Additional file Tables S3). The selection of three full-length unigenes together with their homologs from the three toxin families was then directly analysed using yn00.

To analyze the 3-FTxs, five unigenes were first divided into three groups: 3-FTx(1, 2, 3), 3-FTx(4), and 3-FTx(5). The results indicated that the null hypothesis, the nearly neutral model (M1), could be easily rejected in favour of the positive selection model (M2) in the three tests, with all $P<0.001$ following Bonferroni correction (Table 2). Moreover, $28-45 \%$ codon sites were found to have experienced positive selection with $6.13 \leq \omega \leq 9.59$. The single-ratio model (M0) indicated that all sites and branches of sequence experienced an average strength of selection with $2.81 \leq \omega \leq 3.48$. 
Table 2

Summary of codeml tests for positive selection of toxins from venom-gland transcriptome in $H$. curtus.

\begin{tabular}{|c|c|c|c|c|c|c|c|c|c|c|c|c|}
\hline \multirow{2}{*}{$\begin{array}{l}\text { Toxins (No.) } \\
\text { 3-FTx }(1,2,3)\end{array}$} & \multicolumn{3}{|c|}{ M1: Nearly neutral } & \multirow{2}{*}{$\begin{array}{l}-\ln L \\
748.17\end{array}$} & \multicolumn{4}{|c|}{ M2: Positive selection } & \multirow{2}{*}{$\begin{array}{l}-\ln L \\
735.24\end{array}$} & \multirow{2}{*}{$\begin{array}{l}\text { Mo: } \omega \\
2.81\end{array}$} & \multirow{2}{*}{$\frac{\Delta^{\mathrm{a}}}{25.86}$} & \multirow{2}{*}{$\frac{P \text {-value }}{2.4 \times 10^{-6 *}}$} \\
\hline & $p:$ & 0.28 & 0.72 & & $p:$ & 0.17 & 0.39 & 0.45 & & & & \\
\hline & $\omega:$ & 0.00 & 1.00 & & $\omega:$ & 0.00 & 1.00 & 6.13 & & & & \\
\hline \multirow[t]{2}{*}{$3-\mathrm{FTx}(4)$} & $p:$ & 0.26 & 0.74 & 804.61 & $p:$ & 0.05 & 0.52 & 0.43 & 783.22 & 3.48 & 42.78 & $5.1 \times 10^{-10 *}$ \\
\hline & $\omega:$ & 0.00 & 1.00 & & $\omega:$ & 0.00 & 1.00 & 8.76 & & & & \\
\hline \multirow[t]{2}{*}{$3-\mathrm{FTx}(5)$} & $p:$ & 0.51 & 0.49 & 652.06 & $p:$ & 0.35 & 0.37 & 0.28 & 632.67 & 2.86 & 38.78 & $3.8 \times 10^{-9} \star$ \\
\hline & $\omega:$ & 0.00 & 1.00 & & $\omega:$ & 0.00 & 1.00 & 9.59 & & & & \\
\hline \multirow[t]{2}{*}{ CTL (1) } & $p:$ & 0.30 & 0.70 & 843.02 & $p:$ & 0.19 & 0.74 & 0.06 & 840.70 & 0.21 & 4.64 & 0.10 \\
\hline & $\omega:$ & 0.00 & 1.00 & & $\omega:$ & 0.00 & 1.00 & 24.33 & & & & \\
\hline \multirow[t]{2}{*}{ CTL (2) } & $p:$ & 0.64 & 0.36 & 1221.13 & $p:$ & 0.84 & 0.00 & 0.16 & 1212.49 & 0.58 & 17.28 & $1.8 \times 10^{-4 \star}$ \\
\hline & $\omega:$ & 0.05 & 1.00 & & $\omega:$ & 0.22 & 1.00 & 3.50 & & & & \\
\hline \multirow[t]{2}{*}{ CTL (3) } & $p:$ & 0.15 & 0.85 & 1160.65 & $p:$ & 0.40 & 0.00 & 0.60 & 1148.75 & 2.43 & 23.80 & $6.8 \times 10^{-6 *}$ \\
\hline & $\omega:$ & 0.00 & 1.00 & & $\omega:$ & 0.17 & 1.00 & 4.52 & & & & \\
\hline \multirow[t]{2}{*}{ CTL (4) } & $p:$ & 0.53 & 0.47 & 1201.51 & $p:$ & 0.50 & 0.44 & 0.07 & 1196.01 & 0.65 & 11.00 & 0.004 \\
\hline & $\omega:$ & 0.00 & 1.00 & & $\omega:$ & 0.00 & 1.00 & 4.91 & & & & \\
\hline \multirow[t]{2}{*}{$\mathrm{PLA}_{2}(1)$} & $p:$ & 0.49 & 0.51 & 978.57 & $p:$ & 0.68 & 0.00 & 0.32 & 973.82 & 0.86 & 9.50 & 0.009 \\
\hline & $\omega:$ & 0.00 & 1.00 & & $\omega:$ & 0.13 & 1.00 & 3.17 & & & & \\
\hline \multirow[t]{2}{*}{$\operatorname{PLA}_{2}(2,3)$} & $p:$ & 0.44 & 0.56 & 967.20 & $p:$ & 0.60 & 0.00 & 0.40 & 949.47 & 2.08 & 35.46 & $2.0 \times 10^{-8 *}$ \\
\hline & $\omega:$ & 0.00 & 1.00 & & $\omega:$ & 0.00 & 1.00 & 6.87 & & & & \\
\hline \multirow[t]{2}{*}{ SVMP (1) } & $p:$ & 0.34 & 0.66 & 4316.80 & $p:$ & 0.85 & 0.00 & 0.15 & 4292.41 & 1.08 & 48.78 & $2.6 \times 10^{-11 *}$ \\
\hline & $\omega:$ & 0.00 & 1.00 & & $\omega:$ & 0.57 & 1.00 & 5.53 & & & & \\
\hline \multirow[t]{2}{*}{ SVMP (2) } & $p:$ & 0.51 & 0.49 & 7561.33 & $p:$ & 0.35 & 0.47 & 0.18 & 7411.20 & 1.30 & 300.26 & $0.00 *$ \\
\hline & $\omega:$ & 0.05 & 1.00 & & $\omega:$ & 0.00 & 1.00 & 5.65 & & & & \\
\hline \multirow[t]{2}{*}{ SVSP (1) } & $p:$ & 0.47 & 0.53 & 2042.88 & $p:$ & 0.41 & 0.55 & 0.04 & 2028.38 & 0.73 & 29.00 & $5.0 \times 10^{-7 \star}$ \\
\hline & $\omega:$ & 0.01 & 1.00 & & $\omega:$ & 0.00 & 1.00 & 7.78 & & & & \\
\hline \multirow[t]{2}{*}{ SVSP (2) } & $p:$ & 0.46 & 0.54 & 3659.22 & $p:$ & 0.30 & 0.47 & 0.23 & 3579.72 & 2.25 & 159.00 & $0.00 *$ \\
\hline & $\omega:$ & 0.00 & 1.00 & & $\omega:$ & 0.00 & 1.00 & 9.49 & & & & \\
\hline \multirow[t]{2}{*}{ 5NT $(1,2)$} & $p:$ & 0.66 & 0.34 & 3064.74 & $p:$ & 0.89 & 0.06 & 0.05 & 3057.77 & 0.40 & 13.94 & $9.4 \times 10^{-4 \star}$ \\
\hline & $\omega:$ & 0.00 & 1.00 & & $\omega:$ & 0.19 & 1.00 & 6.10 & & & & \\
\hline \multirow[t]{2}{*}{ CRISP $(1,2)$} & $p:$ & 0.43 & 0.57 & 2473.69 & $p:$ & 0.28 & 0.56 & 0.16 & 2428.77 & 1.63 & 89.84 & $0.00 *$ \\
\hline & $\omega:$ & 0.00 & 1.00 & & $\omega:$ & 0.00 & 1.00 & 6.69 & & & & \\
\hline \multirow[t]{2}{*}{$\operatorname{NGF}(1,2,3)$} & $p:$ & 0.54 & 0.46 & 2549.71 & $p:$ & 0.60 & 0.30 & 0.10 & 2527.86 & 0.86 & 43.70 & $3.2 \times 10^{-10 *}$ \\
\hline & $\omega:$ & 0.12 & 1.00 & & $\omega:$ & 0.28 & 1.00 & 4.35 & & & & \\
\hline \multirow[t]{2}{*}{ Cystatin } & $p:$ & 0.49 & 0.51 & 823.89 & $p:$ & 0.93 & 0.00 & 0.07 & 816.20 & 0.94 & 15.38 & $4.6 \times 10^{-4 \star}$ \\
\hline & $\omega:$ & 0.00 & 1.00 & & $\omega:$ & 0.48 & 1.00 & 7.57 & & & & \\
\hline $\mathrm{HA}$ & $p:$ & 0.52 & 0.48 & 3349.08 & $p:$ & 0.56 & 0.00 & 0.44 & 3347.91 & 0.54 & 2.34 & 0.31 \\
\hline
\end{tabular}




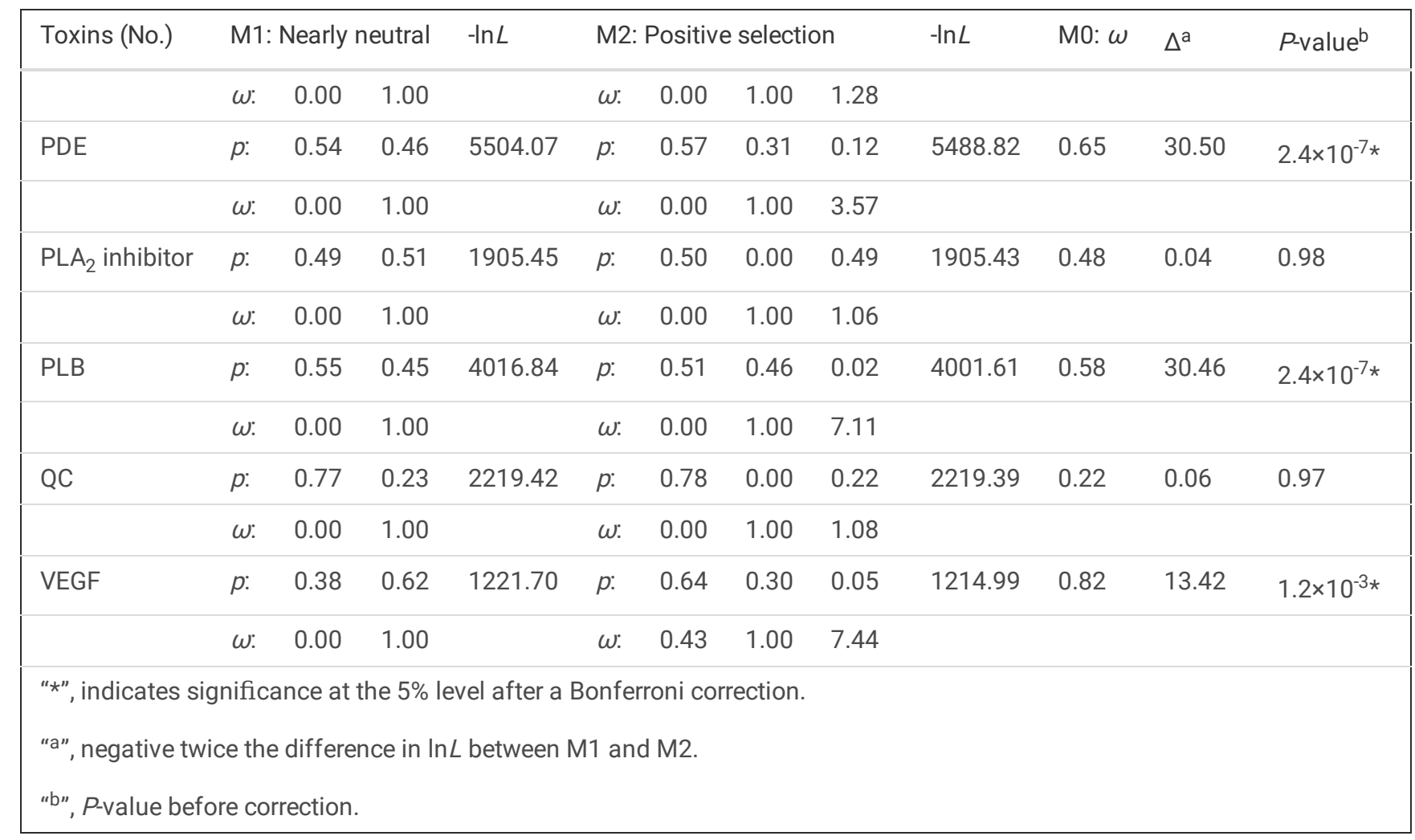

The nucleotide sequence divergence among the four CTL unigenes was $>10 \%$; therefore, these unigenes were analyzed separately with their homologs. In CTL(2) and CTL(3), M1 could be easily rejected in favour of M2, with all $P<0.01$ following Bonferroni correction (Table 2). In addition, $16-60 \%$ codon sites experienced positive selection with $3.50 \leq \omega \leq 4.12$. However, M1 could not be rejected in CTL(1) and CTL(4) with $P>0.05$ in all cases. M0 indicated that all sequence sites and branches experienced an average strength of selection with $0.21 \leq \omega \leq$ 2.43 .

In $\mathrm{PLA}_{2}$, the null hypothesis, $\mathrm{M} 1$, could only be rejected in one group, $\operatorname{PLA}_{2}(2,3)$, in favour of $\mathrm{M} 2$ with $P<0.001$ following Bonferroni correction (Table 2). In addition, $40 \%$ of codon sites experienced positive selection with $\omega=6.87$. The null hypothesis could not be rejected in PLA $(1)$ with $P=0.21$ following Bonferroni correction (Table 2). M0 showed that all sequence sites and branches experienced an average strength of selection of $0.86 \leq \omega \leq 2.08$.

Unigenes from both SVMP and SVSP families all exhibited $>30 \%$ divergence from one another; thus, they were analyzed separately along with their homologs using codeml. For all four tests, M1 could be readily rejected in favour of M2 with all $P<0.001$ following Bonferroni correction (Table 2). Approximately 15-18\% codon sites experienced positive selection with $5.53 \leq \omega \leq 5.56$ in the SVMP family, with estimated values in the SVSP family of $4-23 \%$ codon sites with $7.78 \leq \omega \leq 9.49$. M0 indicated that all sites and branches experienced an average strength of selection with $1.08 \leq \omega \leq 1.30$ in SVMP, whereas that estimated in the SVSP family was $0.73 \leq \omega \leq 2.25$.

The $5 \grave{c}$ NT, CRISP, and NGF families comprised 2-3 unigenes, with sequence divergence within each toxin family below $10 \%$. Thus, the unigenes from the same family were combined for codeml analysis. The results indicated that the null hypothesis, M1, could be rejected in favour of M2 with all $P<0.05$, following Bonferroni correction (Table 2). Additionally, 5\% (5לेNT), 16\% (CRISP), and 10\% (NGF) codon sites experienced positive selection with $4.35 \leq \omega \leq 6.69$. M0 showed that all sequence sites and branches experienced an average strength of selection with $0.40 \leq \omega \leq 1.63$.

Of the remaining families subjected to condeml tests, four (Cystatin, PDE, PLB, and VEGF families) easily rejected the null model, M1, and accepted M2 with $P<0.05$ in all cases following Bonferroni correction (Table 2). For these four tests, an estimated $7 \%, 12 \%, 2 \%$, and $5 \%$ codon sites, respectively, experienced positive selection with $3.57 \leq \omega \leq 7.57$. M0 implied that all sites and branches of the four unigenes on average experienced a selection strength of $0.58 \leq \omega \leq 0.94$. Alternatively, tests for HA, PLA2 inhibitor, and QC unigenes could not reject the null hypothesis, M1, with all $P>0.05$ following Bonferroni correction (Table 2); M0 indicated $\omega$ of $0.54,0.48$, and 0.22 , respectively.

As only one homolog with high similarity could be obtained from the database, maximum-likelihood estimation based on $d N$ and $d S$ of the remaining three unigenes was conducted using the yn00 program. Comparing each pair of sequences, we estimated $d N$ of $0.11,0.04$, and 


\section{Antivenomic, ELISA, and western blotting evaluation of antivenom efficiency}

Using third-generation antivenomic analysis [32] to evaluate the efficacy of commercial monovalent $B$. multicinctus and $N$. atra antivenoms in capturing $H$. curtus venom components, we found that the capacity of $N$. atra antivenom to immunocapture the $H$. curtus venom was stronger than that of $B$. multicinctus antivenom, with increasing abundance of snake venom able to be captured by antivenom as the ratio of antivenom to venom increased (Fig. 4 and Table 3). Based on the ratio of antivenom (20 mg) to venom (50 $\mu$ g) corresponding to approximately 48 -fold molar excess per "10 kDa of toxins", $53.5 \%$ of venom components, comprised mainly of long-neurotoxin (LNX), PLA and CRISP, could be immunocaptured by $B$. multicinctus antivenom, with the non-immunocaptured components including $94.3 \%$ of the SNX being minimally recognized. Comparatively speaking, $90.6 \%$ of the total venom components could be immunocaptured by $N$. atra antivenom (Fig. 4A-E and Table 3). However, when the cross-reaction was conducted between $600 \mu \mathrm{g}$ venom and $20 \mathrm{mg}$ antivenom with a ratio corresponding to approximately 4-fold molar excess per "10 kDa of toxins" (assuming an average molecular mass of $13 \mathrm{kDa}$ for $\mathrm{H}$. curtus venom components), the relative abundance of venom components immunocaptured by the antivenoms decreased dramatically. Specifically, only $17.7 \%$ of total venom components could be recognized by $B$. multicinctus antivenom with the abundance of non-immunocaptured components accounting for 99.1\% SNX (peak 1), 84.8\% PLA P $_{2}$ and long-neurotoxin (peak 5), 83.7\% PLA 2 (peak 6), 89.3\% PLA 2 (peak 8), and $50.4 \%$ CRISP (peak 11), respectively (Fig. 4 U-W and Table 3 ). Similarly, only $27.9 \%$ of the total venom components could be recognized by $N$. atra antivenom, with the abundance of non-immunocaptured components accounting for $84.3 \%$ SNX (peak 1), 83.6\% PLA 2 and longneurotoxin (peak 5), 75.3\% PLA 2 (peak 6), 76.8\% PLA 2 (peak 8), and 75.0\% CRISP (peak 11), respectively (Fig. 4U, X, Y, and Table 3). In the other three reactions, the antivenoms could immunocapture $43.1 \%(100 \mu \mathrm{g}), 35.0 \%(150 \mu \mathrm{g})$, and $30.6 \%(300 \mu \mathrm{g})$ of whole venom by $B$. multicinctus antivenom, and $83.0 \%, 69.6 \%$, and $44.0 \%$ of that by $N$. atra antivenom. 
Table 3

Total and concentration-dependent immunoretained $H$. curtus venom proteins by heterologous

\begin{tabular}{|c|c|c|c|c|c|c|c|}
\hline Fractions & & 50 & 100 & 150 & 300 & 600 & Toxins \\
\hline \multirow[t]{3}{*}{1} & $\mu \mathrm{g}$ Total & 16.56 & 33.13 & 49.69 & 99.38 & 198.77 & 3-FTx(SNX) \\
\hline & $\mu \mathrm{g}$ RET-Bm & 0.95 & 2.94 & 1.18 & 4.17 & 1.82 & \\
\hline & $\mu \mathrm{g}$ RET-Na & 16.56 & 26.48 & 34.36 & 25.62 & 31.13 & \\
\hline \multirow[t]{3}{*}{2} & $\mu \mathrm{g}$ Total & 2.31 & 4.61 & 6.92 & 13.84 & 27.69 & 3-FTx(LNX) \\
\hline & $\mu \mathrm{g}$ RET-Bm & 2.14 & 4.61 & 6.92 & 13.84 & 24.66 & \\
\hline & $\mu \mathrm{g}$ RET-Na & 2.31 & 4.61 & 6.92 & 10.39 & 17.71 & \\
\hline \multirow[t]{3}{*}{3} & $\mu \mathrm{g}$ Total & 1.14 & 2.29 & 3.43 & 6.86 & 13.73 & 3-FTx(LNX) \\
\hline & $\mu \mathrm{g}$ RET-Bm & 1.14 & 2.26 & 3.43 & 6.86 & 12.40 & \\
\hline & $\mu \mathrm{g}$ RET-Na & 1.14 & 2.29 & 3.43 & 5.37 & 8.16 & \\
\hline \multirow[t]{3}{*}{4} & $\mu \mathrm{g}$ Total & 0.17 & 0.34 & 0.50 & 1.01 & 2.01 & 3-FTx(LNX) \\
\hline & $\mu \mathrm{g}$ RET-Bm & 0.17 & 0.34 & 0.50 & 1.01 & 2.01 & \\
\hline & $\mu \mathrm{g}$ RET-Na & 0.17 & 0.34 & 0.48 & 0.92 & 0.93 & \\
\hline \multirow[t]{3}{*}{5} & $\mu g$ Total & 2.05 & 4.10 & 6.15 & 12.3 & 24.6 & $\mathrm{PLA}_{2}+3-\mathrm{FTx}(\mathrm{LNX})$ \\
\hline & $\mu \mathrm{g}$ RET-Bm & 0.81 & 1.38 & 1.53 & 4.03 & 3.73 & \\
\hline & $\mu \mathrm{g}$ RET-Na & 1.04 & 2.16 & 2.15 & 4.03 & 4.02 & \\
\hline \multirow[t]{3}{*}{6} & $\mu \mathrm{g}$ Total & 4.95 & 9.90 & 14.84 & 29.69 & 59.37 & $\mathrm{PLA}_{2}$ \\
\hline & $\mu \mathrm{g}$ RET-Bm & 3.44 & 4.42 & 5.48 & 11.17 & 9.69 & \\
\hline & $\mu \mathrm{g}$ RET-Na & 4.44 & 7.41 & 8.59 & 11.71 & 14.67 & \\
\hline \multirow[t]{3}{*}{7} & $\mu g$ Total & 0.43 & 0.85 & 1.28 & 2.56 & 5.12 & $\mathrm{PLA}_{2}+3-\mathrm{FTx}(\mathrm{LTX})$ \\
\hline & $\mu \mathrm{g}$ RET-Bm & 0.43 & 0.85 & 1.28 & 2.56 & 1.71 & \\
\hline & $\mu \mathrm{g}$ RET-Na & 0.43 & 0.85 & 1.28 & 2.56 & 1.24 & \\
\hline \multirow[t]{3}{*}{8} & $\mu g$ Total & 17.48 & 34.96 & 52.44 & 104.87 & 209.75 & $\mathrm{PLA}_{2}$ \\
\hline & $\mu \mathrm{g}$ RET-Bm & 14.79 & 20.02 & 21.4 & 31.55 & 22.51 & \\
\hline & $\mu \mathrm{g}$ RET-Na & 15.03 & 30.25 & 35.92 & 44.18 & 48.59 & \\
\hline \multirow[t]{3}{*}{9} & $\mu g$ Total & 0.40 & 0.79 & 1.19 & 2.38 & 4.77 & $\mathrm{PLA}_{2}$ \\
\hline & $\mu \mathrm{g}$ RET-Bm & 0.13 & 0.23 & 0.47 & 0.92 & 0.46 & \\
\hline & $\mu \mathrm{g}$ RET-Na & 0.40 & 0.56 & 0.69 & 1.73 & 1.01 & \\
\hline \multirow[t]{3}{*}{10} & $\mu g$ Total & 0.16 & 0.33 & 0.49 & 0.99 & 1.98 & $\mathrm{PLA}_{2}$ \\
\hline & $\mu \mathrm{g}$ RET-Bm & 0.11 & 0.33 & 0.20 & 0.87 & 0.62 & \\
\hline & $\mu \mathrm{g}$ RET-Na & 0.16 & 0.33 & 0.42 & 0.99 & 0.69 & \\
\hline \multirow[t]{3}{*}{11} & $\mu \mathrm{g}$ Total & 4.35 & 8.70 & 13.05 & 26.11 & 52.22 & CRISP \\
\hline & $\mu \mathrm{g}$ RET-Bm & 2.63 & 5.74 & 10.06 & 14.72 & 26.34 & \\
\hline & $\mu \mathrm{g}$ RET-Na & 3.59 & 7.66 & 10.13 & 24.57 & 39.14 & \\
\hline
\end{tabular}

We also found that the capacity of the antivenoms to immunocapture the peak fractions differed and that the immunocapture efficiency changed nonsynchronously as the amount of venom increased (Fig. 4 and Table 3). Additionally, the maximal immunocapturing capacity of 
$N$. atra antivenom for peaks 1,6 , and 8-11 was higher than that of $B$. multicinctus antivenom, whereas the effects were opposite for peaks 24 and comparable for peaks 5 and 7. It could be calculated that $20 \mathrm{mg}$ of immobilized $B$. multicinctus and $N$. atra antivenom presented a maximal immunocapturing capacity of 120.7 and $172.9 \mu \mathrm{H}$. curtus venom, respectively.

A significant cross-reaction between $B$. multicinctus/ $N$. atra antivenom and $H$. curtus venom could be detected by ELISA analysis, with the cross-reactivity showing a progressive increase as the concentration of antivenom increased; moreover, the $N$. atra antivenom presented relatively higher cross-reactivity than that of the $B$. multicinctus antivenom (Fig. 5). A similar capacity was demonstrated using western blotting, another conventional protocol that is commonly used to assess the preclinical efficacy of antivenom. The electrophoretic profile revealed that five significant bands with molecular masses ranging from 8 to $21 \mathrm{kDa}$ could be detected in $H$. curtus venom, of which three (8, 9 , and $11 \mathrm{kDa}$ ) were present high abundance in venom whereas two bands with relatively higher molecular masses of 40 and $60 \mathrm{kDa}$ were expressed at extremely low abundance (Fig. 6A). Protein bands with molecular masses higher than $21 \mathrm{kDa}$ were strongly recognized by $B$. multicinctus and $N$. atra antivenoms but only one $(9 \mathrm{kDa})$ of the three protein bands with the lowest molecular mass could be recognized by these two antivenoms (Fig. 6B and C). The cross-reaction was mainly located in the protein bands with molecular masses of 9,21 , and 40 $\mathrm{kDa}$, with $N$. atra antivenom affording a higher cross-reaction intensity than that from $B$. multicinctus antivenom (Fig. 6B and C). Overall, these results indicated that $N$. atra antivenom presented a higher capacity to immunocapture $H$. curtus venom than $B$. multicinctus antivenom.

\section{Discussion}

Knowledge of venom-gland transcriptomic and venomic profiles is generally considered to be useful in elucidating the evolutionary process and potential function of snake venom, developing antivenom, and even exploring venom-based drugs [33-39]. Notably, the maturation and widespread application of high throughput sequencing and MS technologies have rendered it much easier to unravel the complexity of snake venoms worldwide at the -omics level. In the present study on $\mathrm{H}$. curtus from the South China Sea, 22 and 3 toxin families were identified in the venom-gland transcriptome and venom proteome, respectively, using next-generation sequencing technology and a combined proteomic strategy.

Notably, the composition and abundance of $H$. curtus toxins identified in the present study apparently differed from those in previous investigations either at the mRNA or protein level $[6,8,19]$. For example, the toxin transcripts of the $H$. curtus venom gland was shown to be mainly comprised of 3-FTx, PLA 2 , CRISP, and PDGF families using Sanger sequencing, with the first three families accounting for $55.5 \%$ of the total venom-gland transcriptome and the 3-FTx family expressed more abundantly than PLA $A_{2}$ at a ratio of 4.4:1 [19]. Comparatively speaking, although 3-FTx, PLA 2 , and CRISP transcripts also constituted the most abundant components in the venom-gland transcriptome of $H$. curtus in the present study, accounting for $99.68 \%$ of total toxin transcripts, 3-FTx was less abundant than PLA $A_{2}$ at a ratio of $1: 2.2$. Moreover, 19 novel toxin families expressed with low abundance ( $0.32 \%)$ among total toxin transcripts were also detected. Next-generation sequencing technology therefore appeared to be more powerful than Sanger sequencing for detecting the snake venom-gland transcripts with low abundance. Moreover, the venom protein/mRNA sequence database was relatively insufficient ten years ago, such that a high proportion (24.3\%) of transcripts in a previous study could not be matched to the targeted toxins, potentially resulting in additional toxin families being omitted.

When compared with previously investigated $H$. curtus venoms from Australia and Malaysia $[6,8]$, the venom from the South China Sea population evaluated in the presented study diverged significantly with regard to the relative abundance of predominant toxins at the protein level. The South China Sea population exhibited the lowest abundance of PLA 2 but the highest abundance of 3-FTx, especially SNX, which was approximately 4- and 1.45-fold higher than those from Australia and Malaysia, respectively. Notably, given that SNX was determined to be the most toxic component in $H$. curtus venom [6], the South China Sea population might possess the highest venomic lethality among the three localities.

Moreover, although the venom-gland transcriptome and venom proteome of $H$. curtus were dominated by 3-FTx, PLA 2 , and CRISP families, of which the total abundance expressed at the protein level was highly consistent with that at the mRNA level, an apparent discrepancy was still observed with regard to the composition and abundance of toxins at the family level. Given that comparisons at the family level may not necessarily reflect the mechanisms affecting specific toxin transcripts, a detailed analysis of the correlation between mRNA and protein abundances of 11 toxins for 3-FTx, PLA 2 , and CRISP families was conducted, with the results agreeing with those at the family level. Such discordance between both levels has been observed in many venomous snakes, being potentially attributed to transcriptional, posttranscriptional, translational, or post-translational regulatory mechanisms [11-13,40-43] in addition to the time span between collection of the venom and venom-gland tissue [14]. In contrast, some studies revealed little differential expression of toxins at both -omics levels despite individual variation $[18,44,45]$. Notably, a strong correlation between both mRNA and protein levels was detected in the present study in the remaining toxin transcripts when SNX was excluded. Thus, the mechanisms regulating the mRNA and protein abundances of each toxin from $H$. curtus may differ. Nevertheless, as the majority of $H$. curtus toxins could only be detected at the mRNA but not the protein level, it remains

Page $14 / 28$ 
to be explored whether this phenomenon is regulated by more complex mechanisms such as post-transcriptional silencing and protein buffering.

Considered as a highly effective and biochemically complicated weapon involved in predation, digestion, and defense, snake venom is generally considered to have undergone positive selection during adaptive evolution, which has been successfully estimated at individual toxin and venom-gland transcriptomic levels using different models [46-52]. In practise, positive selection focusing on nucleotide sites of toxin-encoding transcripts has often been detected using site model analysis based on five specific models. The study first conducted in Crotalus adamanteus at the venom-gland transcriptomic level, indicated that a high proportion (89\%, 24/27) of the full-length toxin-coding transcripts underwent positive selection [49]. Similarly, the majority of the toxin transcripts (24/33) from $H$. curtus, accounting for $73 \%$ of the total analyzed transcripts, were deemed in the present study to have experienced positive selection according to the likelihood ratio from $\mathrm{M} 1$ and M2; and it was also verified by M7 and M8 (the results were not shown in this paper as they nearly identical to that from M1 and M2). Consequently, the adaptive evolution of toxin genes from $H$. curtus was likely extensively driven by natural positive selection, even as the diet of $H$. curtus are simpler than those of its terrestrial relatives.

The antivenomic analysis approach based on venomic profile, originally developed as an in vitro platform to qualitatively and quantitatively assess the efficacy of antivenom, has since been updated to the 3rd generation and displays a powerful potential as a substitute for many traditional strategies to evaluate antivenom efficacy [32]. Similar to several recently reported studies using 3rd generation antivenomics [5355], the immunocapture capacity of antivenoms in the present study increased as the incubation amount of $H$. curtus venom increased but varied according to different venom components. Overall, $N$. atra antivenom exhibited higher capacity to immunocapture whole $H$. curtus venom than $B$. multicinctus antivenom, especially for SNX, PLA 2 , and CRISP. However, the former demonstrated a relatively lower capability to immunocapture the LNX. This suggests that $N$. atra antivenom possesses a greater abundance of F(ab') $)_{2}$ to efficiently recognize $H$. curtus venom than $B$. multicinctus antivenom at the same dose, but the amounts of $F\left(a b^{\prime}\right)_{2}$ to recognize specific venom components are likely different between these two antivenoms. This divergence was also roughly verified by western blotting and ELISA analyses. Moreover, western blotting analysis indicated that the capacity of both antivenoms to recognize the venom components with low molecular mass ( $\leq 15 \mathrm{kDa}$ ) was relatively weaker than that for recognizing high molecular mass components, with no ability to recognize the components with molecular masses of 8 and $11 \mathrm{kDa}$. This might be due to the lack of homologous components between $B$. multicinctus/ $N$. atra and $H$. curtus venoms, or because components with low molecular mass generally induce limited or no antibodies because of their weak immune response.

Given the high similarity in venom composition among closely related snakes, appropriate heterologous antivenoms to treat envenomations caused by snakes with no commercial antivenom might be selected according to the phylogenetic relationship. For example, patients envenomed by sea snakes including $H$. curtus have been often been treated by $B$. multicinctus and $N$. atra antivenoms in some hospitals in China [28]. However, based on the antivenomic profiles generated in the present study, $N$. atra antivenom appears to be more suitable for treatment of patients envenomed by $H$. curtus than $B$. multicinctus antivenom, although the phylogenetic relationship between $H$. curtus and B. multicinctus is much closer than that between $H$. curtus and $N$. atra [56]. Thus, the phylogenetic relationship should not be a unique criterion for selection of alternative antivenoms in clinic treatment of snakebites.

Specifically, based on the maximal immunocapture capacity, one vial of commercial B. multicinctus (approximately $57 \mathrm{mg} / \mathrm{mL}, 10 \mathrm{~mL} / \mathrm{vial}$ ) and $N$. atra $(124 \mathrm{mg} / \mathrm{mL}, 10 \mathrm{~mL} / \mathrm{vial})$ antivenoms theoretically could be inferred to absorb 3.4 and $10.7 \mathrm{mg} H$. curtus venom components, respectively, which appeared to approximate $28 \%$ and $89 \%$ of the average venom yield of 12.0 mg (lyophilized venom, calculated from six specimens in the present study). However, it should be noted that the maximal amount of venom components immunocaptured by the antivenoms may not be equal to that of whole venom; e.g., $20 \mathrm{mg} N$. atra antivenom could maximally absorb $172.9 \mu \mathrm{g}$ venom components but only absorbed $69.6 \%$ of $150 \mu \mathrm{g}$ whole $\mathrm{H}$. curtus venom. Moreover, both antivenoms only exhibited high immunocapture efficiency when incubated with relatively low amounts of venom, with up to $53.5 \%$ and $90.6 \%$ of the total amount of $50 \mu \mathrm{g}$ venom being absorbed by $B$. multicinctus and $N$. atra antivenoms, respectively. The abundance of unabsorbed venom components increased as the ratio of antivenom to venom decreased, especially for SNX, the most toxic component in $H$. curtus venom [6]. Consistent with this, the clinical efficacy of both $B$. multicinctus and $N$. atra antivenoms in the treatment of sea snake envenomations has also been relatively poor [28]. Accordingly, the development and application of species-specific antivenom against $H$. curtus venom in China is urgently needed.

\section{Conclusion}

An integrated omics-strategy was used to reveal the venom-gland transcriptomic, venomic, and antivenomic profiles of $H$. curtus from the South China Sea. Our findings verify discordance between the venom-gland transcriptome and venom proteome in $H$. curtus. Briefly, the venom evolved to as a 'biochemically simple' weapon at the protein level to adapt to the simplified diet available when the sea snake returned to the marine environment; conversely, the toxin transcripts with high diversity in the venom-gland transcriptome of $H$. curtus could be defined as a 'genetically complicated' mixture at the mRNA level. In addition, the majority of the full-length toxin-coding unigenes may have 
experienced positive selection in the evolutionary history. Although $N$. atra antivenom has a stronger capability to immunocapture $H$. curtus venom components than does $B$. multicinctus antivenom, both antivenoms only exhibit high immunocapture efficiency when they are incubated with relatively low amounts of venom. Thus, the clinical application of commercial $N$. atra and $B$. multicinctus antivenoms is not recommended in treatment of patients envenomed by $H$. curtus. Rather, the development and application of species-specific antivenom of $H$. curtus venom is urgently required in China. Taken together, our results provide a foundation for additional studies of population-specific venom molecular and evolutionary analyses and the development of effective $H$. curtus antivenom.

\section{Methods}

\section{Venom and antivenoms}

We obtained six adult specimens of $H$. curtus as by-catch in the South China Sea and transported them to our laboratory at Hainan Tropical Ocean University, and maintained them in a circulating sea water system for venom extraction. Fresh venom from individual snakes was extracted repeatedly at a 15-day interval using a 100- $\mu$ l plastic pipette, centrifuged to remove impurities for $15 \mathrm{~min}$ at $10,000 \mathrm{~g} 4{ }^{\circ} \mathrm{C}$, lyophilized, pooled equally, and stored at $-80^{\circ} \mathrm{C}$ until use. Commercial monovalent B. multicinctus antivenom (batch 20070601 , expiry date: 06/2010) and $N$. atra antivenom (batch 20070601, expiry date: 06/2010) consisting of purified $F($ abç) 2 fragments from the plasma of hyperimmunized horses were purchased from Shanghai Serum Biological Technology Co., Ltd., China. Both antivenoms were subdivided, lyophilized, and stored at $-80^{\circ} \mathrm{C}$ immediately upon receipt in the laboratory. Snakes were collected under the permit (2017-09-12) issued by Hainan Tropical Ocean University, and our experimental procedures was approved by the Animal Research Ethics Committee of Hangzhou Normal University (AREC2019109).

\section{Venom gland cDNA synthesis and sequencing}

The snakes were sacrificed for venom-gland transcriptomic analysis when sufficient crude venom was accumulated. After the last round of venom extraction, the snakes were allowed to recover for four days to maximize the venom gland transcription and then anesthetized heavily with sodium pentobarbital (s.c. $30 \mathrm{mg} / \mathrm{kg}$ ) until they showed no tail-retraction reflex. Two venom glands of each snake were removed and split into pieces with a diameter of $<2 \mathrm{~mm}$, then pooled and permeated with RNAlater ${ }^{\circledR}$ (Qiagen) at $4{ }^{\circ} \mathrm{C}$ overnight before transferring to $-80{ }^{\circ} \mathrm{C}$ storage until use. The snakes then were euthanized by injection of sodium pentobarbital (s.c. $100 \mathrm{mg} / \mathrm{kg}$ ), and the carcasses were preserved with $10 \%$ formalin and deposited in the animal collections of Hainan Tropical Ocean University. Total RNA of the pooled venom gland tissue from each sample was isolated using TRIzol (Life Technologies) according to the manufacturer's instructions. RNA was purified, concentrated, and then resuspended in $100 \mu \mathrm{l}$ THE Ambion ${ }^{\circledR}$ RNA storage solution (Life Technologies). The degree of contamination and degradation of RNA in each sample was monitored by $1 \%$ agarose gel electrophoresis. The purity and integrity of RNA was assessed using a Implen NanoPhotometer and Agilent 2100 Bioanalyzer system, respectively, whereas the concentration of RNA was measured using a Qubit 2.0 fluorometer. Subsequently, an RNA mixture for sequencing was prepared by mixing equal amounts of RNA from the above six samples.

The cDNA library for RNA sequencing was generated using the NEBNext ${ }^{\circledR}$ Ultra ${ }^{T M}$ RNA Library Prep Kit for Illumina ${ }^{\circledR}$ (New England Biolabs) according to the manufacturer's instructions. In brief, mRNA was purified and enriched from total RNA with oligo (dT)-attached magnetic beads. Then, the mRNA was fragmented and used as a template to synthesize first-strand cDNA with reverse transcriptase (RNase $H$ ) and random hexamer primers. The following step for synthesizing second-strand cDNA was conducted with dNTPs, RNase H and DNA polymerase I based on first-strand cDNA. The resultant double-stranded cDNA was purified using AMPure XP beads (Beckman Coulter) and subjected to the processes of end repair and ligation of a poly (A) tail and adapters. The adapter-ligated fragments were preferentially screened for those at 250-300 bp in length, amplified by PCR, and purified using AMPure XP beads to create the final cDNA library. Quality of the library was assessed using the Agilent 2100 Bioanalyzer system. High throughout sequencing of the cDNA library was performed using the Illumina HiSeq ${ }^{\mathrm{TM}} 2500$ platform at Novogene Bioinformatics Technology Co., Ltd., China (www.novogene.cn).

\section{Transcriptome assembly, annotation, and quantification}

Prior to transcriptome assembly, raw reads (raw data) from Illumina sequencing were cleaned by eliminating the reads containing adapters and $>10 \%$ unknown sequences ('N's), as well as the reads with low quality $(\mathrm{Q} \leq 20)$. The clean reads (remaining reads) were assembled into contigs using Trinity based on Inchworm, Chrysalis, and Butterfly modules [57]. Initially, clean reads were grouped into different read sets and assembled into a k-mer dictionary $(k=25)$, which was then developed into a collection of linear contigs by greedily searching using Inchworm. If the contigs shared at least one $k-1$-mer and the reads spanned the junction between contigs, they were pooled and built into de Bruijn graphs using Chrysalis. Finally, the de Bruijn graphs with clean reads and paired-end reads were reconciled and the full-length transcripts for spliced isoforms and paralogous sequences were reconstructed and arranged using Butterfly. Subsequently, the longest sequence with no

Page $16 / 28$ 
redundancy was generated from the transcripts in each gene locus by Corset and defined as a unigene, which was used as a reference for downstream analyses. Gene annotation was performed by BLAST searching against the NCBI NT database and Diamond searching against the NCBI NR and UniProt protein databases (strict to the taxa Serpentes). The E-value threshold was set to $1 \times 10^{-5}$. To estimate the abundance of unigenes, all clean reads were initially matched with the reference unigenes using RSEM [58]. The number of reads matched to a given unigene was defined as the readcount, which was then calculated as FPKM [59] for evaluating the abundance.

\section{Isolation and characterization of venom proteins}

Venom powder ( $3 \mathrm{mg}$ ) collected from the six snakes was reconstituted in $0.1 \%$ TFA and centrifuged for $15 \mathrm{~min}$ at $10,000 \mathrm{~g}, 4^{\circ} \mathrm{C}$. The supernatant was collected and applied to a Kromasil 300 RP-C18 column $(250 \times 4.6 \mathrm{~mm}, 5 \mu \mathrm{m}$; AkzoNobel $)$ using a Waters E600 HPLC system. The venom proteins were separated at a flow rate of $1 \mathrm{ml} / \mathrm{min}$ with a mobile phase system of $0.1 \%$ TFA in water (solution A) and $100 \%$ ACN (solution B) at the following linear gradient: $0-15 \%$ B for $30 \mathrm{~min}$, followed by $15-45 \%$ B for 120 min and $45-70 \%$ B for 20 min. Protein detection was conducted at $215 \mathrm{~nm}$. Fractions were collected and concentrated in a CentriVap ${ }^{\circledR}$ Centrifugal Concentrator (Labconco). Protein concentrations of venom fractions were determined according to the Bradford method [60]. The proteins in each fraction were separated by $18 \%$ SDS-PAGE. The gels were stained in $0.2 \%$ CBB R-250 and scanned using a UMAx2100 densitometer.

Protein bands in the gels were excised, destained with $0.1 \mathrm{M} \mathrm{NH}_{4} \mathrm{HCO}_{3}$ in $30 \% \mathrm{ACN}$, rinsed with $0.1 \mathrm{M} \mathrm{NH}_{4} \mathrm{HCO}_{3}$, and then digested with trypsin (Promega) for $20 \mathrm{~h}$ at $37^{\circ} \mathrm{C}$. The peptide mixture was lyophilized, and re-dissolved in $2 \mu \mathrm{l}$ of $20 \% \mathrm{ACN}$. The solution was spotted onto a sample holder and air-dried, to which $0.5 \mu \mathrm{l}$ of $5 \mathrm{mg} / \mathrm{ml}$ a-cyano-4-hydroxycinnamic acid (ABI) in $50 \%$ ACN and $0.1 \%$ TFA was added; then, the sample was dried completely and subjected to ABI 4800 Plus MALDI-TOF/TOF-MS mass spectrometer according to the instruction manual. For LC-MS/MS analysis, the peptide mixture was re-dissolved in $0.1 \%$ TFA and desalted using a Zorbax 300 SB-C18 column (150 $\times$ $0.3 \mathrm{~mm}, 5 \mu \mathrm{m}$; Agilent Technologies), then separated by reverse phase capillary HPLC using an RP-C18 column $(150 \times 0.15 \mathrm{~mm}, 5 \mu \mathrm{m}$; Column Technology Inc.) with a mobile phase system of $0.1 \%$ FA in water (solution A) and $84 \%$ ACN in $0.1 \%$ FA (solution B) as follows: $4-50 \%$ B for $30 \mathrm{~min}$, followed by $50-100 \%$ B for $4 \mathrm{~min}$ and $100 \%$ B for $1 \mathrm{~min}$. The eluted peptides were applied to a Q Exactive mass spectrometer according to the manufacturer's instructions. The raw MS/MS spectra were interpreted using FlexAnalysis or Xcalibur software and the assignment of amino acid sequence similarity was executed using PEAKS X against the UniProt Serpentes database or an in-house database constructed using toxin transcripts extracted from the H. curtus venom-gland transcriptome. The mass tolerance was set at 0.4 Da for MALDITOF/TOF-MS and 0.1 Da for LC-MS/MS. Carbamidomethyl (C) was set as a fixed modification and oxidation (M) was set as a variable modification.

Integration of the collected HPLC fractions and densitometry of the protein bands in the SDS-PAGE electropherogram were used to estimate the relative abundance of venom composition according to Calvete et al. [61]and Shan et al. [62]. Briefly, the relative abundance of fractions was calculated by peak area measurement using Empower software. When the fractions presented only one protein band in SDS-PAGE, the relative abundance was directly obtained from the peak area measurement, whereas for the fractions presenting more than one protein band, the relative abundance of each band was estimated by densitometry using Tan4100 software.

\section{Detection of adaptive molecular evolution}

Tests of adaptive molecular evolution were performed on the transcripts with full-length CDS from 18 toxin families using positive selection analysis. Prior to analysis, sequences homologous to transcripts were obtained from the NCBI NT database with an approximate threshold of $10 \%$ nucleotide sequence divergence. Sequences were aligned using Geneious 4.8 .3 on the basis of the amino-acid sequence. Gaps, stop codons, and signal peptides were excluded from all analyses. The best-fitting model for partitions was determined using PartitionFinder 1.1.1 [63] based on the Bayesian Information Criterion and greedy search. Then, a Bayesian phylogeny was constructed using BEAST 2.2 [64] and each analysis was conducted by performing four replicate searches with 100 million generations, retaining trees every 10,000 generations. The chains were ensured to converge and mix adequately using Tracer 2.2. The maximum clade credibility tree for the target tree was obtained using the TreeAnnotator 2.2 suite, with the first $10 \%$ of sampled generations being excluded.

A likelihood-ratio test for positive selection was performed using codeml in PAML 4.8, based on five models [65] as follows. The nearly neutral model (M1), which is defined as the null model, allows for a group of sites to have experienced neutral selection $(d N / d S=1)$ and another group to be constrained under purifying selection $(d N / d S<1)$ in evolutionary history. The positive model (M2), which is defined as the alternative model, advances an additional parameter that can indicate the group of sites that experienced positive selection $(d N / d S>1)$. To test whether a group of sites experienced positive selection, the difference in log likelihoods between these two models was compared to a $\chi^{2}$ distribution with two degrees of freedom. A similar test by comparing models M7 (beta) and M8 (beta with positive selection) was conducted to verify the initial results, using a $\chi^{2}$ distribution with two degrees of freedom. An overall $d N / d S$ was indicated by the M0 model, which

Page $17 / 28$ 
introduces a single ratio for all sites based on an average $d N / d S$ across the entire phylogeny. If the transcript could only be aligned with one full-length homolog from the database, then $d N$ and $d S$ were directly analyzed by yn00 in PAML 4.8, and the $d N / d S$ value for selection assessment was calculated manually.

\section{Antivenomics analysis}

The capability of commercial monovalent $B$. multicinctus antivenom and $N$. atra antivenom to recognize $H$. curtus venom was assessed using the third-generation antivenomics analysis [32]. The antivenom was dissolved and dialyzed against MilliQ water, then lyophilized and redissolved in coupling buffer $\left(0.2 \mathrm{M} \mathrm{NaHCO}_{3}, 0.5 \mathrm{M} \mathrm{NaCl}, \mathrm{pH} 8.3\right)$. An immunoaffinity column coupled with $B$. multicinctus or $N$. atra antivenom was prepared simultaneously. CNBr-activated Sepharose 4B matrix (1 ml) (GE Healthcare) was packed in a $3 \mathrm{ml}$ column and washed with $15 \mathrm{CV}$ (matrix volumes) of $1 \mathrm{mM}$ ice-cold $\mathrm{HCl}$, followed by $3 \mathrm{CV}$ of coupling buffer. The matrix was incubated overnight at $4{ }^{\circ} \mathrm{C}$ in $0.5 \mathrm{CV}$ of coupling buffer containing $70 \mathrm{mg}$ antivenom. To calculate the antivenom coupling yield, the concentrations of antivenom before and after incubation with the matrix were determined spectrophotometrically at $280 \mathrm{~nm}$ based on an extinction coefficient ( $\varepsilon$ ) of 1.36 for 1 $\mathrm{mg} / \mathrm{ml}$ protein in a $1 \mathrm{~cm}$ light path length. The matrices of the two columns were coupled with $20.1 \mathrm{mg}$ B. multicinctus and $20.5 \mathrm{mg}$ N. atra $\mathrm{F}(\mathrm{abc})_{2}$ antivenom fragments. After the coupling, the non-reacting groups were blocked gently with $1 \mathrm{CV}$ of blocking buffer (0.1 M Tris- $\mathrm{HCl}$, $\mathrm{pH}$ 8.0) for $4 \mathrm{~h}$ at room temperature on an orbital shaker. Both columns containing matrix were alternately washed with six repetitions of $3 \mathrm{CV}$ of low (0.1 M acetate buffer, $0.5 \mathrm{M} \mathrm{NaCl}, \mathrm{pH} 4.0)$ and high ( $0.1 \mathrm{M}$ Tris- $\mathrm{HCl}, \mathrm{pH} 8.5) \mathrm{pH}$ buffer and equilibrated with $3 \mathrm{CV}$ of binding buffer (20 $\mathrm{mM}$ PBS, pH 7.2). Finally, the matrix coupled with $20 \mathrm{mg}$ of antivenom was retained in each column. For immunoaffinity analysis, $0.5 \mathrm{ml}$ binding buffer containing 50,100,150,300, and $600 \mu \mathrm{g} \mathrm{H}$. curtus venom was loaded onto the column and incubated gently for $1 \mathrm{~h}$ at room temperature on an orbital shaker. After recovering the non-retained venom fractions using $3 \mathrm{CV}$ binding buffer, the retained fractions were eluted and collected with $3 \mathrm{CV}$ of $0.1 \mathrm{M}$ glycine- $\mathrm{HCl}, \mathrm{pH} 2.0$, and immediately brought to neutral $\mathrm{pH}$ with $1 \mathrm{M} \mathrm{Tris-} \mathrm{HCl}(\mathrm{pH} 9.0)$. Both nonretained and retained fractions were concentrated using a CentriVap ${ }^{\circledR}$ Centrifugal Concentrator and analyzed by RP-HPLC as described above.

\section{Enzyme-linked immunosorbent assay (ELISA)}

Microplates (96 wells) were coated with $100 \mu \mathrm{H}$. curtus venom proteins $\left(2 \mu \mathrm{g} / \mathrm{ml}\right.$ in $\left.0.1 \mathrm{M} \mathrm{Na}_{2} \mathrm{CO}_{3}-\mathrm{NaHCO}_{3}, \mathrm{pH}^{9.6}\right)$ per well overnight at $4{ }^{\circ} \mathrm{C}$. The unbound proteins were washed off with PBST (0.05\% Tween-20 in $10 \mathrm{mM} \mathrm{PBS,} \mathrm{pH} \mathrm{7.4)} \mathrm{and} \mathrm{the} \mathrm{plate} \mathrm{was} \mathrm{blocked} \mathrm{with} 150 \mu \mathrm{l} \% \mathrm{BSA}$ in PBST at $37^{\circ} \mathrm{C}$ for $1 \mathrm{~h}$. After washing three times, $100 \mu$ of serially diluted horse serum/commercial B. multicinctus/ N. atra antivenom (initial concentration $4 \mu \mathrm{g} / \mu \mathrm{l}$ ) in PBST containing $1 \%$ BSA was added into each well and incubated at $37^{\circ} \mathrm{C}$ for $1 \mathrm{~h}$. Subsequently, the plate was washed again and 1:10000 diluted HRP-labelled anti-horse IgG (Sigma) was added into each well and incubated at $37^{\circ} \mathrm{C}$ for $1 \mathrm{~h}$. Finally, the unbound secondary antibodies were thoroughly rinsed from the plate with PBST. Aliquots (100 $\mu \mathrm{l})$ of substrate solution ( $0.5 \mathrm{mg} / \mathrm{ml}$ OPD and $0.006 \% \mathrm{H}_{2} \mathrm{O}_{2}$ in $0.15 \mathrm{M}$ citrate buffer, $\mathrm{pH}$ 5.0) was added to each well and incubated at room temperature for 20 min. The reaction was stopped with $50 \mu \mathrm{l} 2.5 \mathrm{M}$ sulphuric acid and the absorbance was recorded at $490 \mathrm{~nm}$ using a SpectraMax 384 microplate reader.

\section{Western blotting}

Venom proteins of $\mathrm{H}$. curtus were separated by 18\% SDS-PAGE under reduced conditions according to Laemmli (1970). After electrophoresis, the proteins on the gel were either transferred to a PVDF membrane ( $0.45 \mu \mathrm{m}$, Millipore) in a semi-dry system (Bio-Rad) or stained with CBB R250. The membrane was then blocked with 5\% BSA in TBST (20 mM Tris- $\mathrm{HCl} \mathrm{pH} \mathrm{8.0,} \mathrm{containing} 150 \mathrm{mM} \mathrm{NaCl}$ and $0.05 \% \mathrm{Tween}-20$ ) overnight at $4{ }^{\circ} \mathrm{C}$. After washing with TBST, the membrane was incubated with 1:500 diluted commercial antivenom at $37{ }^{\circ} \mathrm{C}$ for $1 \mathrm{~h}$. Then, the membrane was washed and incubated with 1:3000 diluted HRP-labelled antihorse IgG at $37^{\circ} \mathrm{C}$ for $1 \mathrm{~h}$. After washing off the unbound secondary antibodies, the membrane was incubated with Pierce ${ }^{\mathrm{TM}}$ ECL western blotting substrate and exposed to X-ray film. The film was scanned using a UMax2100 densitometer and analyzed with Tan4100 software.

\section{Statistical analyses}

To detect the correlation between mRNA and protein level abundance of individual genes for each toxin family, the data were centred log-ratio (clr) transformed prior to analyses according to Rokyta et al. [66]. Two coefficients (Spearman's rank correlation coefficient and Pearson's correlation coefficient) used for assessment of correlation were calculated by non-parametric correlation and linear regression analyses using Statistica 8.0. The significance level was set at $a=0.05$

\section{Abbreviations}

Page 18/28 
3-FTx: three finger toxin; $5 \grave{c}$ NT: $5 \dot{c}$ nucleotidase; AchE: acetylcholinesterase; AP: aminopeptidase; Bm, B. multicinctus; CREGF: cysteine-rich EGF-like domain; CRISP: cysteine-rich secretory protein; CTL: C-type lectin; HA: hyaluronidase; $d N$ : nonsynoymous substitution rate; $d s$ : synonymous substitution rate; LAAO: I-amino acid oxidase; LNX, long chain a-neurotoxin; Na, N. atra; NGF: nerve growth factor; PAML: phylogenetic analysis by maximum likelihood; PDE: phosphodiesterase; PLA 2 : phospholipase $A_{2}$; PLB: phospholipase B; QC: glutaminylpeptide cyclotransferases; SNX, short chain a-neurotoxin; SVMP: snake venom metalloproteinase; SVSP: snake venom serine proteinase; VEGF: vascular endothelial growth factor; VF: venom factor.

\section{Declarations}

\section{Ethics approval and consent to participate}

Snakes were collected under the permit (2017-09-12) issued by Hainan Tropical Ocean University, and our experimental procedures was approved by the Animal Research Ethics Committee of Hangzhou Normal University (AREC2019109).

\section{Consent for publication}

Not applicable.

\section{Availability of data and materials}

The venom-gland transcriptome raw data were submitted to the NCBI Sequence Read Archive (SRA) under the accession number PRJNA670846.

\section{Competing interests}

The authors declare that they have no competing interests.

\section{Funding}

This work was supported by grants from the Finance Science and Technology Project of Hainan Province (ZDYF2018120), Natural Science Foundation of China (31471995 and 31770428), Science and Technology Development Plan Project of Hangzhou (20180533B04). The funders had no role in the study design, data collection, analysis and interpretation, decision to publish, and preparation of the manuscript.

\section{Authors' contributions}

JFG and XJ conceived and designed the study. YD, CXL and LHL conducted fieldwork. HYZ, LW, YFM, YS, YY and JFG conducted laboratory and data analysis. HYZ, XJ and JFG wrote and edited the manuscript. All authors reviewed and contributed to editing of the manuscript and approved of its final publication.

\section{Acknowledgements}

We thank Zhong-Yin Chen, Qi-Ze Liu, Jing-Geng Lv, Tao Jiang, Qiang Wang, Yi-Fan Zhao and Zi-Xuan Zhang for help in the laboratory.

\section{References}

1. Karthikeyan R, Balasubramamian T. Species diversity of sea snake (Hydrophiidae) distributed in the coramantal coast (East Coast of India). Int J Zool Res. 2007;3(3):107-31.

2. Rasmussen AR, Murphy JC, Ompi M, Gibbons JW, Uetz P. Marine Reptiles. PLoS One. 2011;6(11):e27373.

3. Tan CH, Tan KY, Lim SE, Tan NH. Venomics of the beaked sea snake, Hydrophis schistosus: a minimalist toxin arsenal and its crossneutralization by heterologous antivenoms. J Proteomics. 2015;126:121-30.

4. Calvete JJ, Ghezellou P, Paiva O, Matainaho T, Ghassempour A, Goudarzi H, Kraus F, Sanz L, Williams DJ. Snake venomics of two poorly known Hydrophiinae: comparative proteomics of the venoms of terrestrial Toxicocalamus longissimus and marine Hydrophis 
cyanocinctus. J Proteomics. 2012;75(13):4091-101.

5. Li M, Fry BG, Kini RM. Eggs-only diet: its implications for the toxin profile changes and ecology of the marbled sea snake (Aipysurus eydouxii). J Mol Evol. 2005;60(1):81-9.

6. Tan $\mathrm{CH}$, Tan KY, Ng TS, Sim SM, Tan NH. Venom proteome of spine-bellied sea snake (Hydrophis curtus) from Penang, Malaysia: toxicity correlation, immunoprofiling and cross-neutralization by sea snake antivenom. 2019;11(1):3.

7. Durban J, Sasa M, Calvete JJ. Venom gland transcriptomics and microRNA profiling of juvenile and adult yellow-bellied sea snake, Hydrophis platurus, from Playa del Coco (Guanacaste, Costa Rica). 2018;153:96-105.

8. Neale V, Sotillo J, Seymour J, Wilson D. The venom of the spine-bellied sea snake (Hydrophis curtus): proteome, toxin diversity and intraspecific variation. Int J Mol Sci. 2017;18(12):2695.

9. Tan KY, Tan CH, Fung SY, Tan NH. Neutralization of the principal toxins from the venoms of Thai Naja kaouthia and Malaysian Hydrophis schistosus: insights into toxin-specific neutralization by two different antivenoms. 2016;8(4):86.

10. Lomonte B, Pla D, Sasa M, Tsai W-C, Solórzano A, Ureña-Díaz JM, Fernández-Montes ML, Mora-Obando D, Sanz L, Gutiérrez JM, et al. Two color morphs of the pelagic yellow-bellied sea snake, Pelamis platura, from different locations of Costa Rica: snake venomics, toxicity, and neutralization by antivenom. J Proteomics. 2014;103:137-52.

11. Rodrigues RS, Boldrini-França J, Fonseca FPP, de la Torre P, Henrique-Silva F, Sanz L, Calvete JJ, Rodrigues VM. Combined snake venomics and venom gland transcriptomic analysis of Bothropoides pauloensis. J Proteomics. 2012;75(9):2707-20.

12. Margres MJ, McGivern JJ, Wray KP, Seavy M, Calvin K, Rokyta DR. Linking the transcriptome and proteome to characterize the venom of the eastern diamondback rattlesnake (Crotalus adamanteus). J Proteomics. 2014;96:145-58.

13. Tan CH, Tan KY, Fung SY, Tan NH. Venom-gland transcriptome and venom proteome of the Malaysian king cobra (Ophiophagus hannah). BMC Genomics. 2015;16(1):1-21.

14. Modahl CM, Frietze S, Mackessy SP. Transcriptome-facilitated proteomic characterization of rear-fanged snake venoms reveal abundant metalloproteinases with enhanced activity. J Proteomics. 2018;187:223-34.

15. Xu N, Zhao H-Y, Yin Y, Shen S-S, Shan L-L, Chen C-X, Zhang Y-X, Gao J-F, Ji X. Combined venomics, antivenomics and venom gland transcriptome analysis of the monocoled cobra (Naja kaouthia) from China. J Proteomics. 2017;159:19-31.

16. Casewell NR, Wagstaff SC, Wüster W, Cook DAN, Bolton FMS, King SI, Pla D, Sanz L, Calvete JJ, Harrison RA. Medically important differences in snake venom composition are dictated by distinct postgenomic mechanisms. Proc Natl Acad Sci U S A. 2014;111(25):9205-10.

17. Aird SD, da Silva NJ Jr, Qiu L, Villar-Briones A, Saddi VA, de Campos Telles PM, Grau ML, Mikheyev AS. Coralsnake venomics: analyses of venom gland transcriptomes and proteomes of six Brazilian taxa. Toxins. 2017;9(6):187.

18. Hofmann EP, Rautsaw RM, Strickland JL, Holding ML, Hogan MP, Mason AJ, Rokyta DR, Parkinson CL. Comparative venom-gland transcriptomics and venom proteomics of four Sidewinder Rattlesnake (Crotalus cerastes) lineages reveal little differential expression despite individual variation. Sci Rep. 2018;8(1):15534.

19. Pahari S, Bickford D, Fry BG, Kini RM. Expression pattern of three-finger toxin and phospholipase $A_{2}$ genes in the venom glands of two sea snakes, Lapemis curtus and Acalyptophis peronii: comparison of evolution of these toxins in land snakes, sea kraits and sea snakes. BMC Evol Biol. 2007;7:175.

20. Rasmussen AR. Sea snakes. In: Carpenter KE, and Niem VH, editors. FAO species identification guide for fishery purposes//The living marine resources of the Western Central Pacific. Rome, Food and Agriculture Organization of the United Nations; 2001;6:3988-4008.

21. Wand N-P, Li Q-B, Li B-Y, Li Z-Y, Li H-P, Tang S-X, Sawai Y, Kawanura Y, Toriba M, Kobayashi T. An epidemiological study on the snakebites in Guangxi proince, China in 1990 (in Chinese). J Snake. 1993;5(1):10-7.

22. Cao NV, Tao NT, Moore A, Montoya A, Rasmussen AR, Broad K, Voris HK, Takacs Z. Sea snake harvest in the gulf of Thailand. Conserv Biol. 2014;28(6):1677-87.

23. Milton DA, Fry GC, Dell Q. Reducing impacts of trawling on protected sea snakes: by-catch reduction devices improve escapement and survival. Mar Freshwater Res. 2009;60(8):824-32.

24. Phillips CM. Sea snake envenomation. Dermatol Ther. 2002;15(1):58-61.

25. Tu AT, Fulde G. Sea snake bites. Clin Dermatol. 1987;5(3):118-26.

26. World Health Organization. Guidelines for the production, control and regulation of snake antivenom immunoglobulins. In: WHO Expert Committee on Biological Standardization Sixty-seventh Report Annex 5 (WHO Technical Report Series, No 964). Geneva, World Health Organization of the United Nations; 2018.

27. White J. A clinician's guide to Australian venomous bites and stings: incorporating the updated CSL antivenom handbook. Parkville, Australia CSL Ltd.; 2013. 
28. Zeng Z-Y, Wu Z-M, Wu X-Z. Observation of clinic efficacy of Sheduqing mixture on treatment of bites by sea snakes (in Chinese). J Snake. 2012;24(1):22-3.

29. Li Y, Tao H, Zhang L-M, Tuo Y. Progress in medical aid to the snakebites caused by sea snake (in Chinese). Nurs J Chin People's Liberation Army. 2003;20(11):55-6.

30. Zhao E-M. Snakes of China (in Chinese). Heifei, Anhui Science and Technology Publishing House; 2006.

31. Anisimova M, Bielawski JP, Yang Z-H. Accuracy and power of the likelihood ratio test in detecting adaptive molecular evolution. Mol Biol Evol. 2001;18(8):1585-92.

32. Calvete JJ, Sanz L, Angulo Y, Lomonte B, Gutiérrez JM. Venoms, venomics, antivenomics. FEBS Lett. 2009;583(11):1736-43.

33. Georgieva D, Öhler M, Seifert J, von Bergen M, Arni RK, Genov N, Betzel C. Snake venomic of Crotalus durissus terrificus-correlation with pharmacological activities. J Proteome Res. 2010;9(5):2302-16.

34. Calvete JJ. Snake venomics: from the inventory of toxins to biology. Toxicon 2013;75:44-62.

35. Lomonte B, Fernandez J, Sanz L, Angulo Y, Sasa M, Gutierrez JM, Calvete JJ. Venomous snakes of Costa Rica: biological and medical implications of their venom proteomic profiles analyzed through the strategy of snake venomics. J Proteomics. 2014;105:323-39.

36. Gao J-F, Wang J, He Y, Qu Y-F, Lin L-H, Ma X-M, Ji X. Proteomic and biochemical analyses of short-tailed pit viper (Gloydius brevicaudus) venom: age-related variation and composition-activity correlation. J Proteomics. 2014;105:307-22.

37. Tan NH, Fung SY, Tan KY, Yap MKK, Gnanathasan CA, Tan CH. Functional venomics of the Sri Lankan Russell's viper (Daboia russelii) and its toxinological correlations. J Proteomics. 2015;128:403-23.

38. Xie B, Huang Y, Baumann K, Fry B, Shi Q. From marine venoms to drugs: efficiently supported by a combination of transcriptomics and proteomics. Mar Drugs. 2017;15(4):103.

39. Valente RH, Guimarães PR, Junqueira M, Neves-Ferreira AGC, Soares MR, Chapeaurouge A, Trugilho MRO, León IR, Rocha SLG, OliveiraCarvalho AL et al. Bothrops insularis venomics: a proteomic analysis supported by transcriptomic-generated sequence data. $J$ Proteomics. 2009;72(2):241-55.

40. Corrêa-Netto C, Junqueira-de-Azevedo IdLM, Silva DA, Ho PL, Leitão-de-Araújo M, Alves MLM, Sanz L, Foguel D, Zingali RB, Calvete JJ. Snake venomics and venom gland transcriptomic analysis of Brazilian coral snakes, Micrurus altirostris and corallinus. J Proteomics. 2011;74(9):1795-809.

41. Durban J, Juárez P, Angulo Y, Lomonte B, Flores-Diaz M, Alape-Girón A, Sasa M, Sanz L, Gutiérrez J, Dopazo J et al. Profiling the venom gland transcriptomes of Costa Rican snakes by 454 pyrosequencing. BMC Genomics. 2011;12:259.

42. Durban J, Pérez A, Sanz L, Gómez A, Bonilla F, Rodríguez S, Chacón D, Sasa M, Angulo Y, Gutiérrez JM et al. Integrated "omics" profiling indicates that miRNAs are modulators of the ontogenetic venom composition shift in the Central American rattlesnake, Crotalus simus simus. BMC Genomics. 2013;14:234.

43. Wagstaff SC, Sanz L, Juárez P, Harrison RA, Calvete JJ. Combined snake venomics and venom gland transcriptomic analysis of the ocellated carpet viper, Echis ocellatus. J Proteomics. 2009;71(6):609-23.

44. Aird SD, Watanabe Y, Villar-Briones A, Roy MC, Terada K, Mikheyev AS. Quantitative high-throughput profiling of snake venom gland transcriptomes and proteomes (Ovophis okinavensis and Protobothrops flavoviridis). BMC Genomics. 2013;14:790.

45. Lynch VJ. Inventing an arsenal: adaptive evolution and neofunctionalization of snake venom phospholipase $\mathrm{A}_{2}$ BMC Evol Biol. $2007 ; 7: 2$.

46. Gibbs HL, Rossiter W. Rapid evolution by positive selection and gene gain and loss: PLA 2 venom genes in closely related Sistrurus rattlesnakes with divergent diets. J Mol Evol. 2008;66(2):151-66.

47. Casewell NR, Wagstaff SC, Harrison RA, Renjifo C, Wüster W. Domain loss facilitates accelerated evolution and neofunctionalization of duplicate snake venom metalloproteinase toxin genes. Mol Biol Evol. 2011;28(9):2637-49.

48. Rokyta DR, Wray KP, Lemmon AR, Lemmon EM, Caudle SB. A high-throughput venom-gland transcriptome for the eastern diamondback rattlesnake (Crotalus adamanteus) and evidence for pervasive positive selection across toxin classes. Toxicon. 2011;57(5):657-71.

49. Margres MJ, Aronow K, Loyacano J, Rokyta DR. The venom-gland transcriptome of the eastern coral snake (Micrurus fulvius) reveals high venom complexity in the intragenomic evolution of venoms. BMC Genomics. 2013;14:531.

50. Rokyta DR, Wray KP, Margres MJ. The genesis of an exceptionally lethal venom in the timber rattlesnake (Crotalus horridus) revealed through comparative venom-gland transcriptomics. BMC Genomics. 2013;14:394.

51. McGivern JJ, Wray KP, Margres MJ, Couch ME, Mackessy SP, Rokyta DR. RNA-seq and high-definition mass spectrometry reveal the complex and divergent venoms of two rear-fanged colubrid snakes. BMC Genomics. 2014;15:1061.

52. Pla D, Rodríguez Y, Calvete JJ. Third generation antivenomics: pushing the limits of the in vitro preclinical assessment of antivenoms. 2017;9(5):158. 
53. Sanz L, Quesada-Bernat S, Chen P-Y, Lee C-D, Chiang J-R, Calvete JJ. Translational venomics: third-generation antivenomics of antisiamese Russell's viper, Daboia siamensis, antivenom manufactured in Taiwan CDC's vaccine center. Trop Med Infect Dis. 2018;3(2):66.

54. Al-Shekhadat RI, Lopushanskaya KS, Segura Á, Gutiérrez JM, Calvete JJ, Pla D. Vipera berus berus venom from Russia: venomics, bioactivities and preclinical assessment of microgen antivenom. Toxins. 2019;11(2):90.

55. Deka A, Gogoi A, Das D, Purkayastha J, Doley R. Proteomics of Naja kaouthia venom from North East India and assessment of Indian polyvalent antivenom by third generation antivenomics. J Proteomics. 2019;207:103463.

56. Pyron RA, Burbrink FT, Wiens JJ. A phylogeny and revised classification of Squamata, including 4161 species of lizards and snakes. BMC Evol Biol. 2013;13:93.

57. Grabherr MG, Haas BJ, Yassour M, Levin JZ, Thompson DA, Amit I, Adiconis X, Fan L, Raychowdhury R, Zeng Q et al. Full-length transcriptome assembly from RNA-Seq data without a reference genome. Nat biotechnol. 2011;29(7):644-52.

58. Li B, Dewey CN. RSEM: accurate transcript quantification from RNA-Seq data with or without a reference genome. BMC Bioinformatics. 2011;12:323.

59. Dutta S, Chanda A, Kalita B, Islam T, Patra A, Mukherjee AK. Proteomic analysis to unravel the complex venom proteome of eastern India Naja naja: correlation of venom composition with its biochemical and pharmacological properties. J Proteomics. 2017;156:29-39.

60. Bradford MM. A rapid and sensitive method for the quantitation of microgram quantities of protein utilizing the principle of protein-dye binding. Anal Biochem. 1976;72(1-2):248-54.

61. Calvete JJ, Juárez P, Sanz L. Snake venomics. Strategy and applications. J Mass Spectrom. 2007;42(11):1405-14.

62. Shan L-L, Gao J-F, Zhang Y-X, Shen S-S, He Y, Wang J, Ma X-M, Ji X. Proteomic characterization and comparison of venoms from two elapid snakes (Bungarus multicinctus and Naja atra) from China. J Proteomics. 2016;138:83-94.

63. Lanfear R, Calcott B, Ho SYW, Guindon S. PartitionFinder: combined selection of partitioning schemes and substitution models for phylogenetic analyses. Mol Biol Evol. 2012;29(6):1695-701.

64. Bouckaert R, Heled J, Kühnert D, Vaughan T, Wu C-H, Xie D, Suchard MA, Rambaut A, Drummond AJ. BEAST 2: a software platform for Bayesian evolutionary analysis. PLOS Comput Biol. 2014;10(4):e1003537.

65. Yang Z-H. PAML 4: phylogenetic analysis by maximum likelihood. Mol Biol Evol. 2007;24(8):1586-91.

66. Rokyta DR, Margres MJ, Calvin K. Post-transcriptional mechanisms contribute little to phenotypic variation in snake venoms. G3Genes|Genom|Genet. 2015;5(11):2375-82.

\section{Figures}

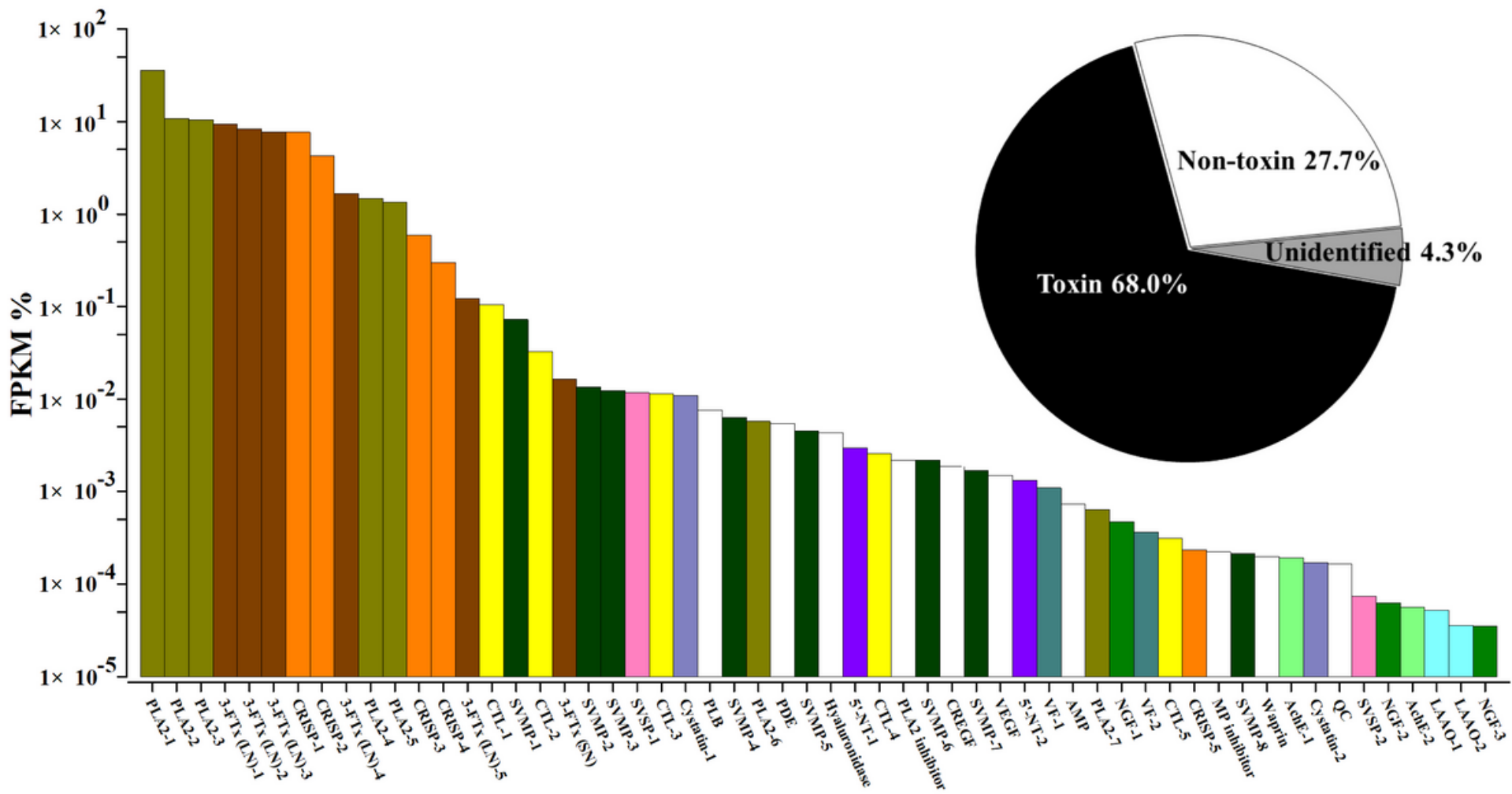


Figure 1

Venom-gland transcriptomic profiles of H. curtus. The details are listed in Additional file Tables S1 and S2. 3-FTx, three finger toxin; PLA2, phospholipase A2; CRISP, cysteine-rich secretory protein; CTL, C-type lectin; SVMP, snake venom metalloproteinase; SVSP, snake venom serine proteinase; PLB, phospholipase B; PDE, phosphodiesterase; HA, hyaluronidase; 5'NT, 5' nucleotidase; CREGF, cysteine-rich EGF-like domain; VEGF, vascular endothelial growth factor; VF, venom factor; AP, aminopeptidase; NGF, nerve growth factor; AchE, acetylcholinesterase; QC, glutaminyl-peptide cyclotransferases; LAAO, L-amino acid oxidase.

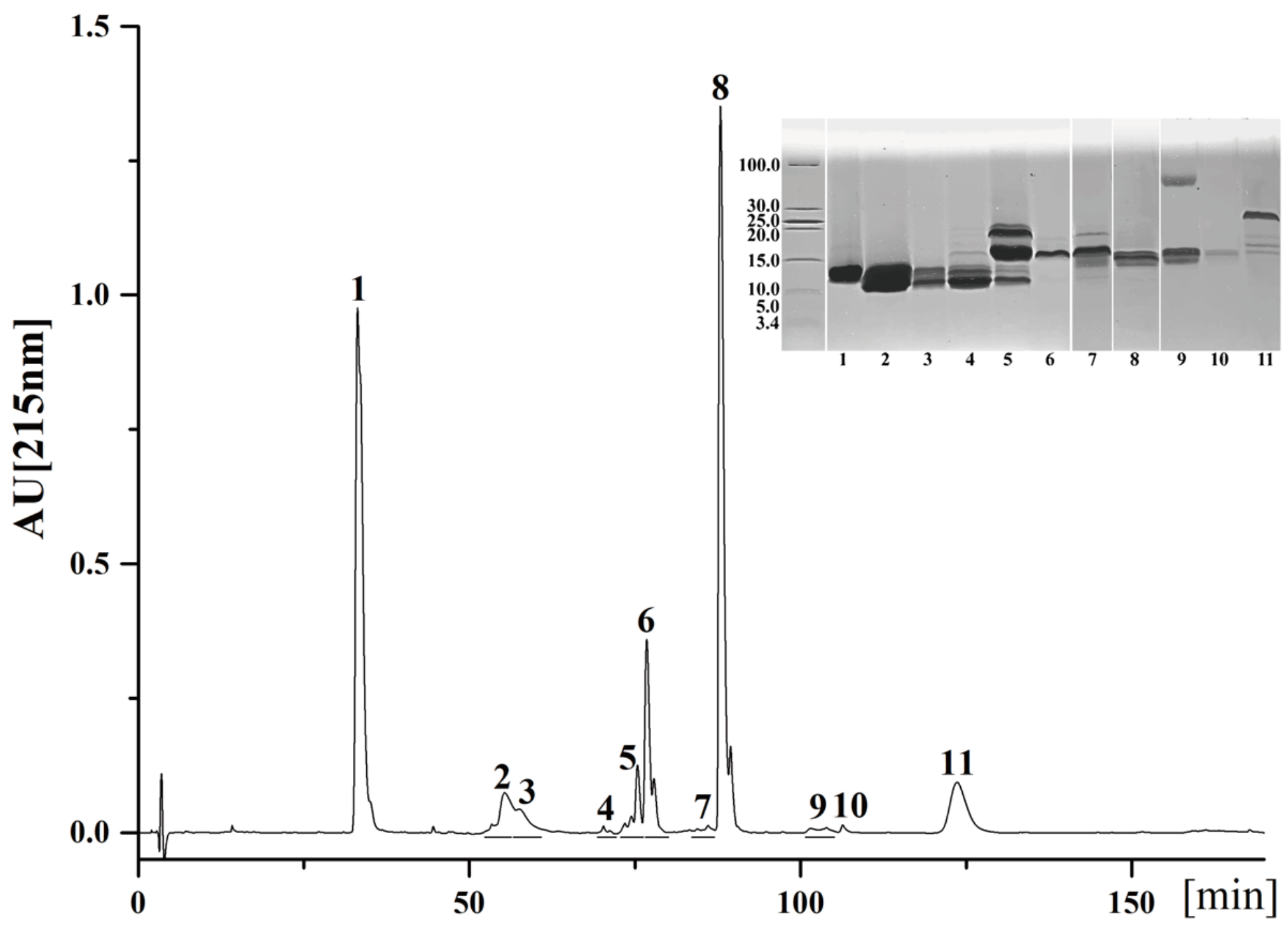

Figure 2

Characterization of the venom proteins of $\mathrm{H}$. curtus from South China Sea. Three milligrams of total venom were applied to a C18 column, and separated as described on Materials and methods. Fractions were collected manually and submitted to molecular determination by SDSPAGE under reduced conditions. Protein bands were excised, tryptic digested and analyzed by MALDI-TOF/TOF or nESI-MS/MS for their assignment to known protein families. The results are shown in Table 1. 


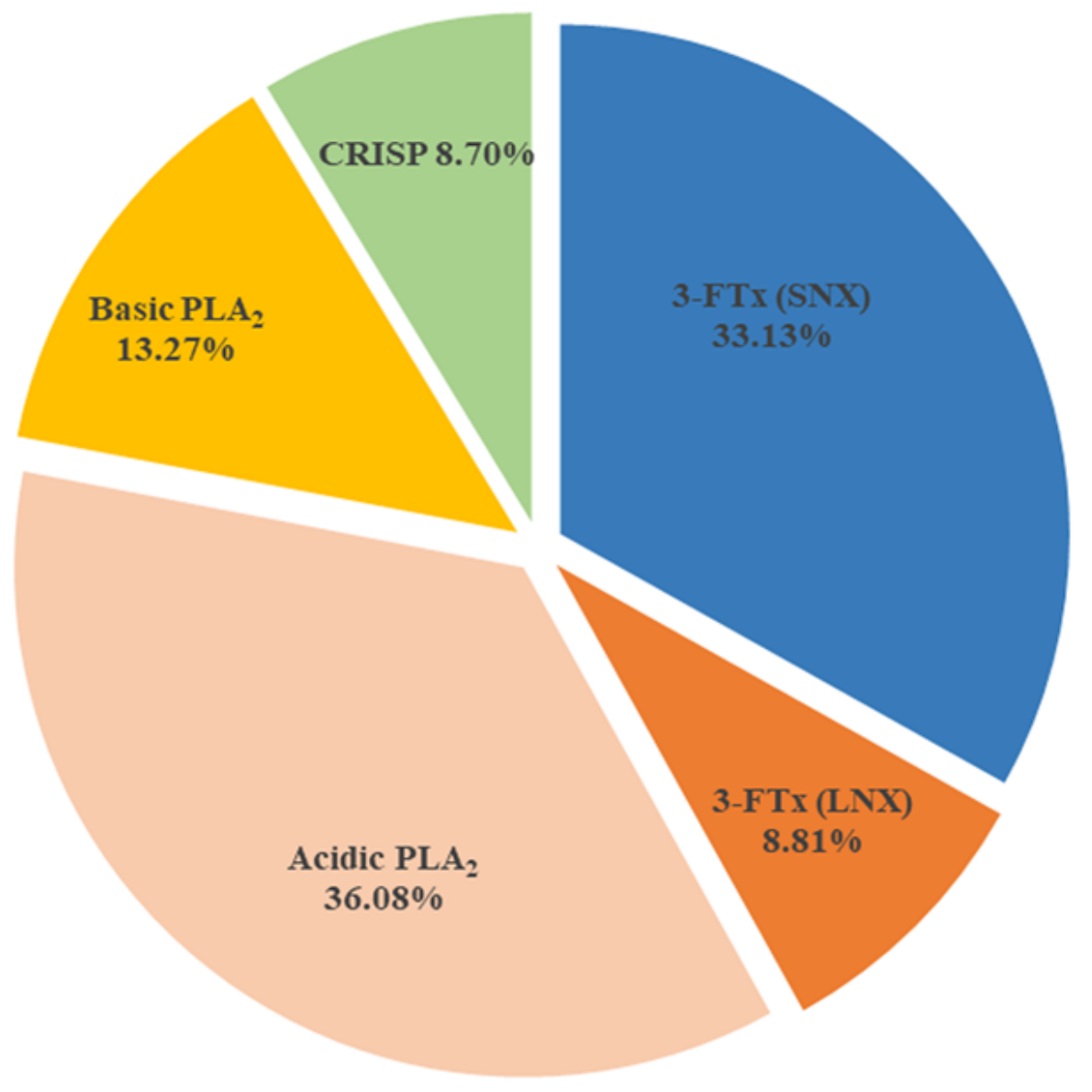

\section{Figure 3}

Venom proteomic profiles of $\mathrm{H}$. curtus. The details are listed in Table 1. 3-FTx, three finger toxin; PLA2, phospholipase A2; CRISP, cysteine-rich secretory protein; LNX, long chain a-neurotoxin; SNX, short chain a-neurotoxin. 


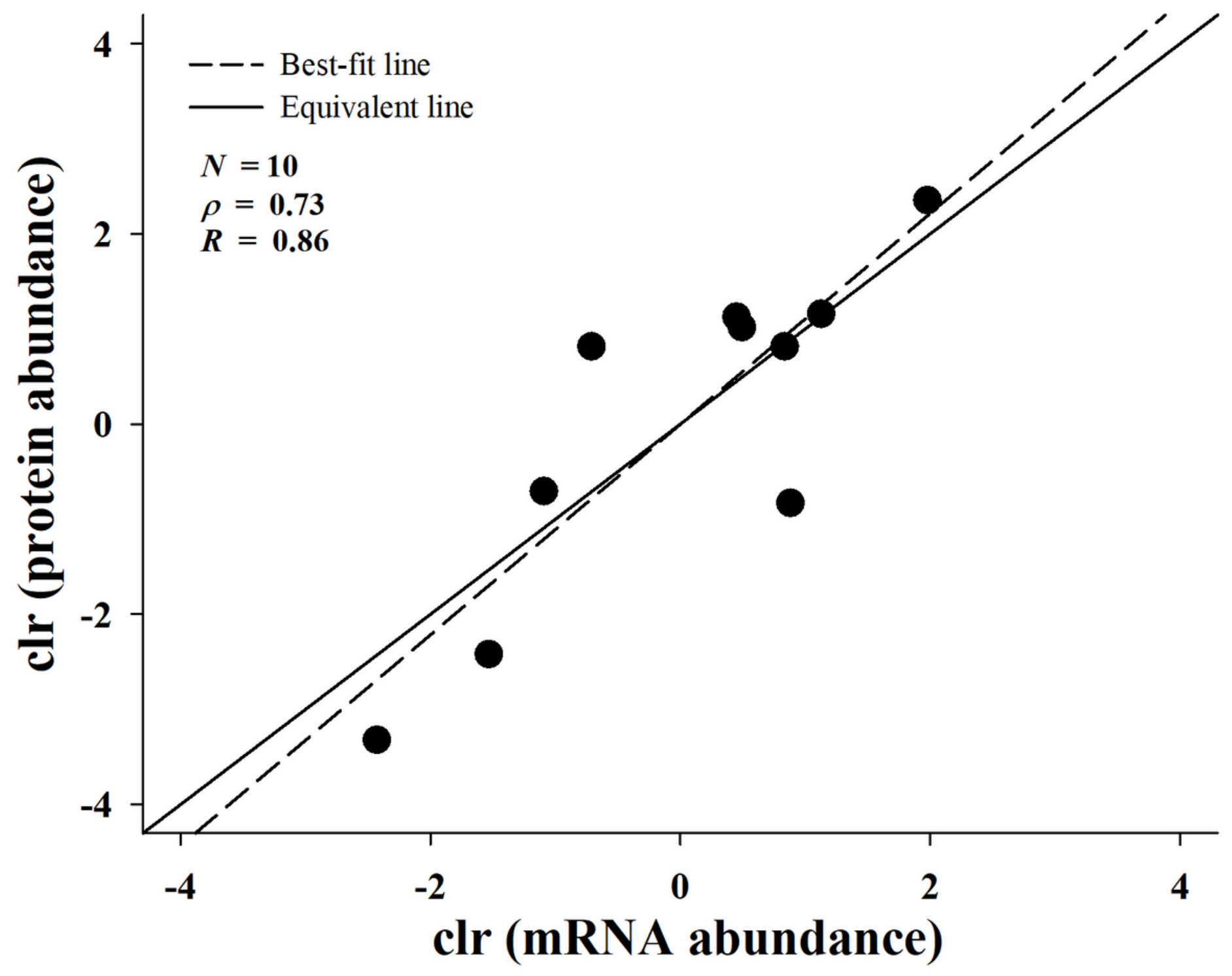

Figure 4

Correlation between mRNA and protein abundances of individual gene for each toxin family. SNX was excluded from the analysis. All data were centered log-ratio (clr) transformed. N, number of toxin transcripts; $\rho$, Spearman's rank correlation coefficient; $R$, Pearson's correlation coefficient. 

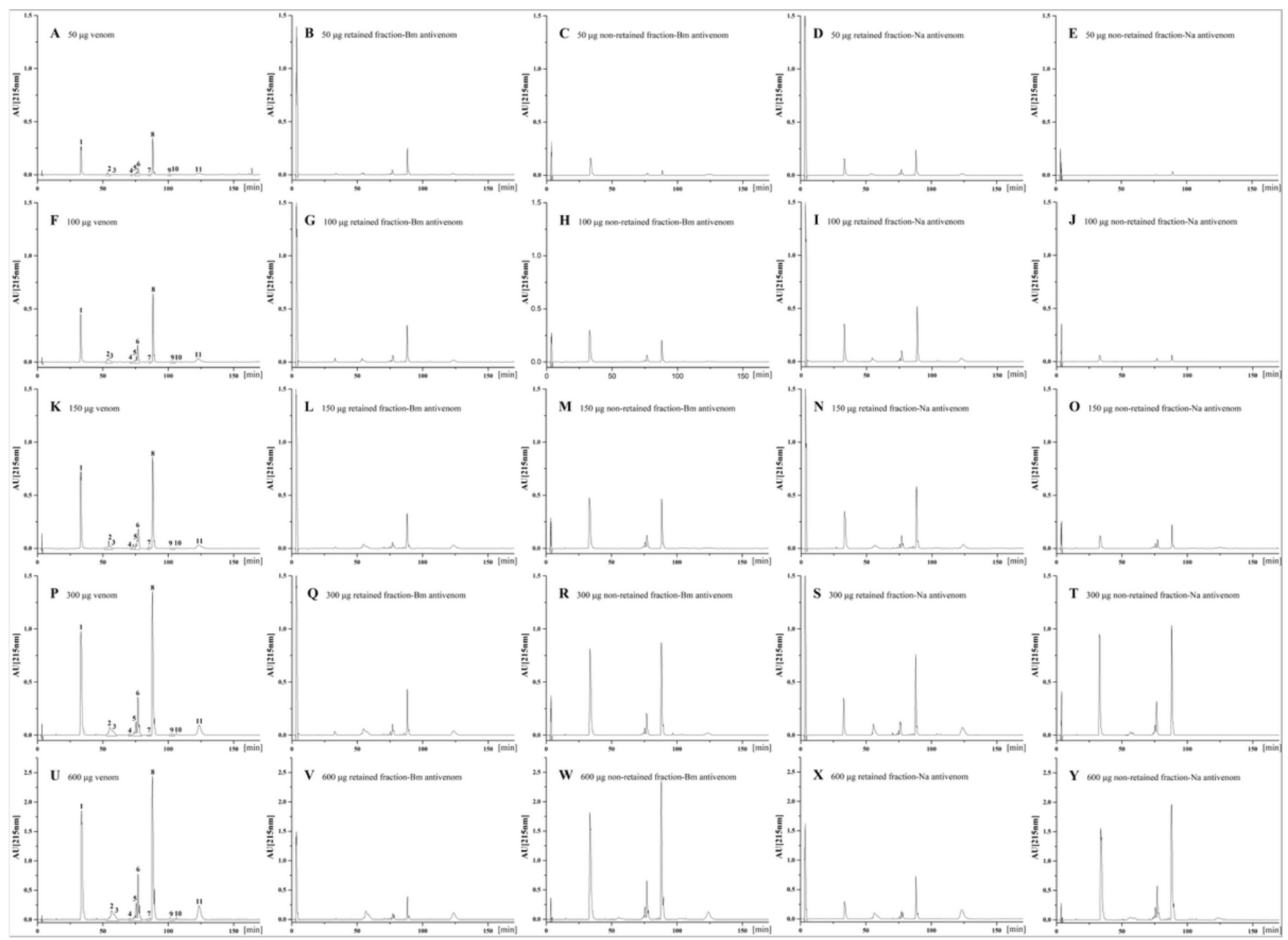

\section{Figure 5}

Antivenomics analysis of $\mathrm{H}$. curtus venom using commercial antivenom by RP-HPLC. Chromatographic profiles of 50, 100, 150, 300 and 600 $\mu \mathrm{g}$ whole venom components (panels $\mathrm{A}, \mathrm{FK}, \mathrm{P}$ and $\mathrm{U}$ ) and, of immunocaptured venom components (panels $\mathrm{B}, \mathrm{D}, \mathrm{G}, \mathrm{I}, \mathrm{L}, \mathrm{N}, \mathrm{Q}, \mathrm{S}, \mathrm{V}$ and $\mathrm{X}$ ) and non-immunocaptured venom components (panels $C, E, H, J, M, O, R, T, W$ and $Y$ ) recovered from the affinity columns after incubation with the corresponding amounts of venom. Bm, B. multicinctus; Na, N. atra. 


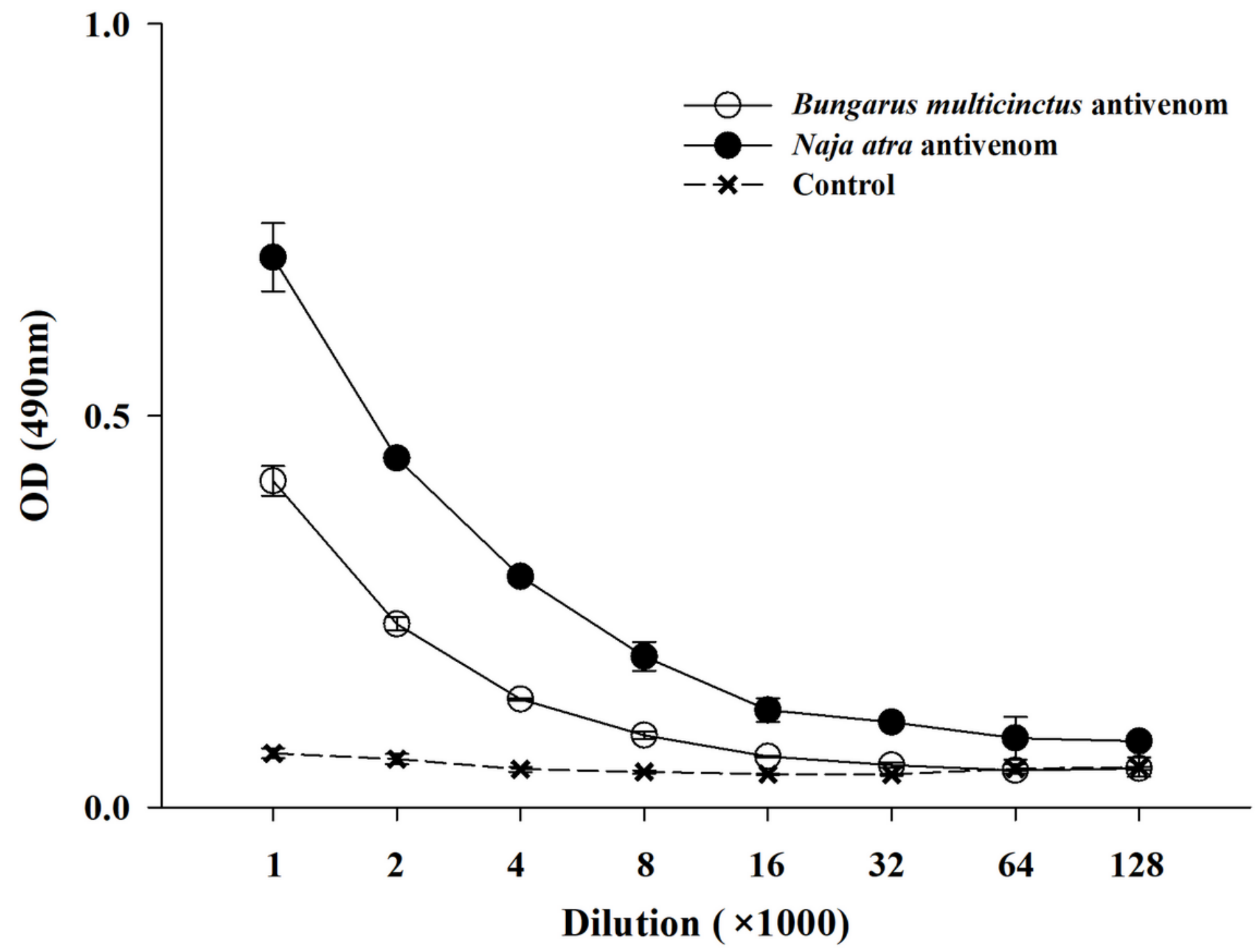

Figure 6

Cross-reaction between $\mathrm{H}$. curtus venom and commercial antivenom determined by ELISA. Normal horse serum was used as negative control. Data are expressed as mean $\pm S D(n=3)$. 


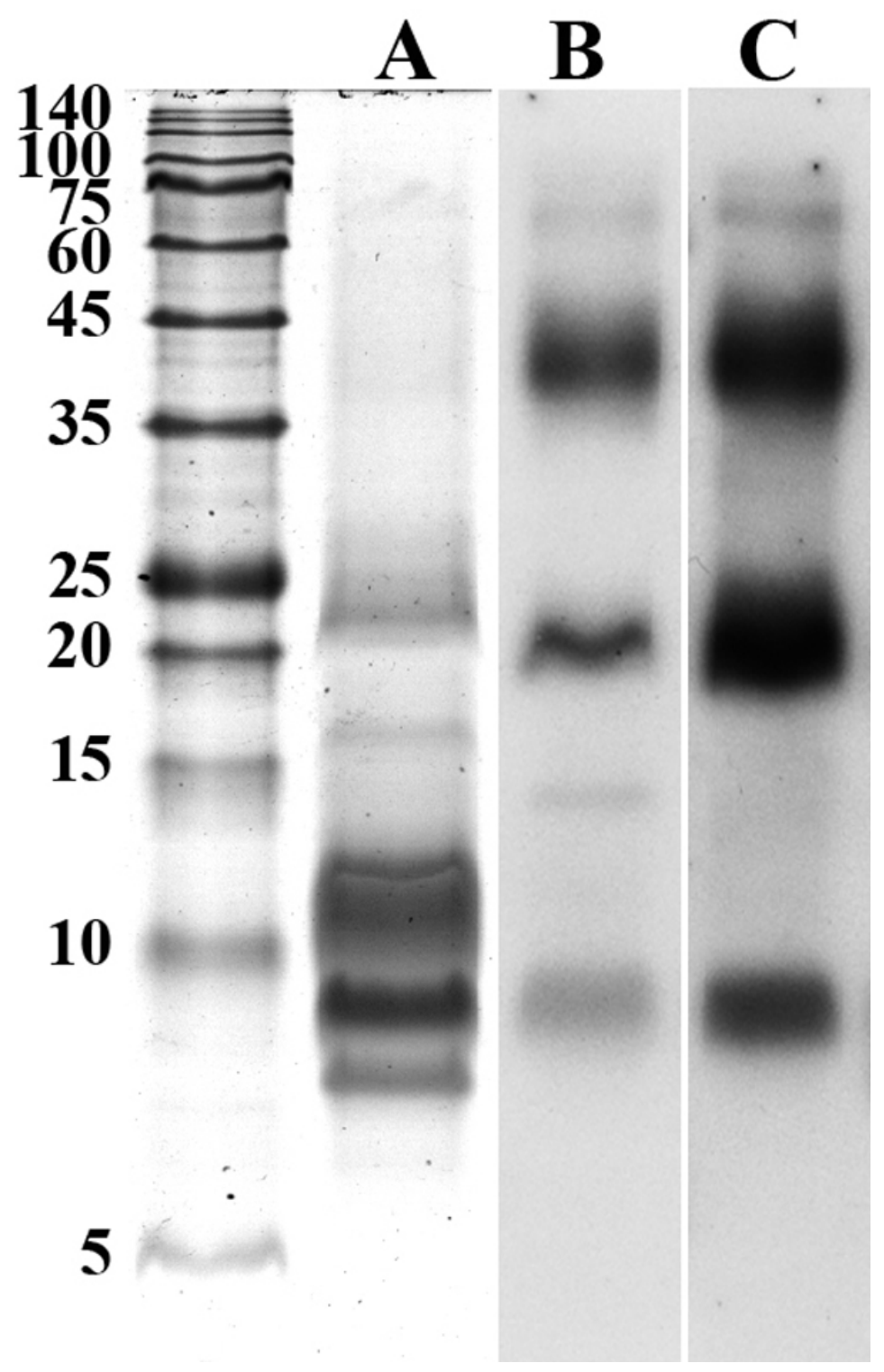

Figure 7

Cross-reaction between $\mathrm{H}$. curtus venom and commercial antivenom determined by western blotting. A, SDS-PAGE profiles of venom protein; B, B. multicinctus antivenom; C, N. atra antivenom.

\section{Supplementary Files}

This is a list of supplementary files associated with this preprint. Click to download.

- ARRIVEGuidenlinesChecklist.pdf

- Additionalfile.xlsx 